\title{
Organic Lewis Pairs Based on Phosphine and Electrophilic Silane for the Direct and Controlled Polymerization of Methyl Methacrylate: Experimental and Theoretical Investigations
} \author{
Karinne MIQUEU, ${ }^{\int *}$ and Daniel TATON ${ }^{\dagger *}$

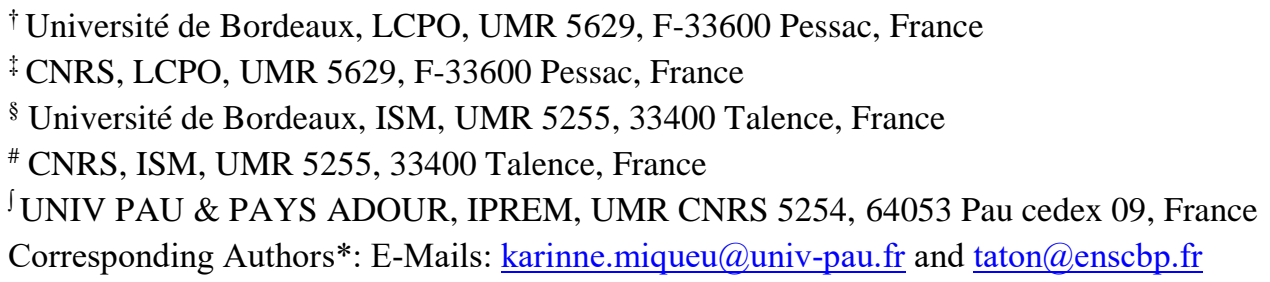

Winnie NZAHOU OTTOU, ${ }^{\dagger}$ Ana PASCUAL, ${ }^{\dagger}$ Damien BOURICHON, ${ }^{\jmath}$ Anne-Laure WIROTIUS, ${ }^{\dagger *}$ Joan VIGNOLLE ${ }^{\dagger \dagger}$ Frédéric ROBERT, ${ }^{\circledR}$ Yannick LANDAIS, ${ }^{\S}$ Jean-Marc SOTIROPOULOS,

Keywords: Phosphine, Silane, Lewis Pair, Metal-free polymerization, Methyl methacrylate, Density Functional Theory

\begin{abstract}
Fully organic Lewis pairs, combining a phosphine such as tris- $n$-butylphosphine $\left(\mathrm{P}^{\mathrm{n}} \mathrm{Bu}_{3}\right)$, tristert-butylphosphine $\left(\mathrm{P}^{\prime} \mathrm{Bu}_{3}\right)$ or tris-(2,4,6-trimethoxyphenyl) phosphine (TTMPP) as a Lewis base, and $\mathrm{N}$-(trimethylsilyl)bis(trifluoromethane sulfonyl)imide $\left(\mathrm{Me}_{3} \mathrm{SiNTf}_{2}\right)$ as a Lewis acid, are shown to directly initiate the polymerization of methyl methacrylate (MMA) at room temperature in toluene. A dual reaction mechanism involving an optimal TTMPP:Me $\mathrm{SiNTf}_{2}$ ratio of 1:2 accounts for the control of the polymerization. Molar masses of poly(methyl methacrylate)'s (PMMA's) can be varied by the initial [MMA $]_{0} /[T T M P P]_{0}$ molar ratio. Chain extension experiments confirm that a majority of chains of a TTMPP/Me $\mathrm{SiNTf}_{2}$-derived PMMA can be reactivated. Both Density Functional Theory (DFT) calculations and stoichiometric studies reveal that TTMPP and $\mathrm{Me}_{3} \mathrm{SiNTf}_{2}$ form a P-silyl phosphonium intermediate that is in equilibrium with the corresponding frustrated Lewis pair (FLP). This FLP could correspond to the active form of the initiation step. Both computational and experimental data support the existence of a cooperative mechanism during the TTMPP/Me $\mathrm{SiNTf}_{2}-$ mediated Lewis pair-mediated polymerization of MMA.
\end{abstract}

\section{INTRODUCTION}

Combining two distinct catalysts in a bi-component system is a powerful strategy, which allows synthesizing complex molecules that would be hardly accessible using a single catalyst. ${ }^{1-7}$ Most examples are based on the association of a metallic complex with an organic catalyst, each partner displaying a specific activity towards the desired transformation. Both catalysts operate by activating the reaction partners in a dual/cooperative manner. ${ }^{1-4}$ In the context of polymer chemistry, dual catalysis has also proven to dramatically increase chain growth polymerization activity and selectivity. ${ }^{8}{ }^{81}$ Early works where some Al-based catalysts have been associated to pyridine for the ring-opening polymerization (ROP) of lactones have been reported in the 1990's. ${ }^{12,13}$ Recent examples of a dual organic/organometallic polymerization catalysis, utilizing a monoor a bicomponent catalytic system, mainly concern the ROP of $D, L$-lactide $(D, L$-LA), trimethylene carbonate or some lactones. ${ }^{14-20}$ The associated ROP mechanism involves activation of the carbonyl group of the heterocyclic monomer and activation of the alcohol initiator by the metallic Lewis acid and the organic base, respectively. A dual organocatalysis ROP, i.e. employing fully organic catalysts, has also been contemplated, again with $D, L-\mathrm{LA}$, as a means to achieve metal-free polyesters. ${ }^{21-25}$

This way of cooperatively catalyzing polymerizations is actually connected to the concept of frustrated Lewis pairs (FLP's), for instance, based on phosphines or $N$-heterocyclic carbenes (NHCs) as Lewis bases (LB's) and boranes as Lewis acids (LA's), regarding the activation of poorly reactive molecular substrates. ${ }^{26-31}$ In FLP's, quenching of each component as it takes place with "classical" Lewis pairs is precluded owing to the 
steric demand around reactive sites. The FLP concept has been recently translated in polymer chemistry to the polymerization of conjugated polar alkenes, including (meth)acrylate derivatives and 2-vinyl-pyridine. ${ }^{11,32-34}$ Typically, a sterically hindered phosphine (or a NHC) as LB associated with $\mathrm{Al}\left(\mathrm{C}_{6} \mathrm{~F}_{5}\right)_{3}$ as LA initiates the polymerization of methyl methacrylate (MMA) with an extremely high turnover frequency (TOF). ${ }^{11,32-34}$ Not only weakly frustrated systems, but also "classical" Lewis pairs, such as $\mathrm{PPh}_{3} / \mathrm{Al}\left(\mathrm{C}_{6} \mathrm{~F}_{5}\right)_{3}$, have eventually proven the most active. ${ }^{11,32-34}$ It is noteworthy in these polymerizations, that the Lewis pair (LP) serves as a direct initiating system, and not as a catalyst as in the dual organic/organometallic or fully organic catalysis discussed above in the context of ROP. ${ }^{14-19}$ Moreover, although the activity of LP/FLP systems is remarkable, the polymerization is not rigorously controlled by the monomer to the Lewis pair molar ratio, and sometimes a relatively broad dispersity can characterize the resulting polymers. Yet, a few examples of a direct LP-initiated polymerization (= LPP), proceeding in a more controlled fashion, have been reported. Bourissou et al. have thus resorted to $\mathrm{Zn}\left(\mathrm{C}_{6} \mathrm{~F}_{5}\right)_{2}$ and pentamethylpiperidine to achieve cyclic PLA's by ROP of $D, L$-LA, ${ }^{35}$ while Chen et al. and $\mathrm{Lu}$ et al. have shown that LPP of methacrylates can be mediated by a NHC in conjunction with $\mathrm{B}\left(\mathrm{C}_{6} \mathrm{~F}_{5}\right)_{3}$. In latter cases, molecular weights of as-obtained polymethacrylates can indeed be tuned by varying the initial monomer to the $\mathrm{NHC}$ ratio. ${ }^{36,37}$

Following our interest both in the catalyzed and non-catalyzed polymerization of (meth)acrylate monomers using organic nucleophiles (e.g. NHCs or phosphines), ${ }^{38-44}$ we wish to report herein that the association of a phosphine, e.g. tris(2,4,6-trimethoxyphenyl)phosphine (TTMPP) as LB, with $N$-(trimethylsilyl)bis(trifluoromethanesulfonyl)imide $\left(\mathrm{Me}_{3} \mathrm{SiNTf}_{2}\right)$ as LA, allows directly initiating the polymerization of MMA. In the context of organic chemistry, silane-based LA's, such as $\mathrm{Me}_{3} \mathrm{SiOTf}$, $\mathrm{Me}_{3} \mathrm{SiNTf}_{2}$, are efficient catalysts for various transformations, ${ }^{45}$ for instance for the Diels-Alder, ${ }^{46-47}$ and the Mukaiyama-aldol ${ }^{48}$ reactions. The use of such electrophilic silanes within FLP's has also been reported for the activation of $\mathrm{CO}_{2} .^{49-51}$ In polymer chemistry, the ability of $\mathrm{Me}_{3} \mathrm{SiNTf}_{2}$ to activate (meth)acrylates monomers has recently been evidenced by Kakuchi et al. in the case of the Group Transfer Polymerization of both acrylates and (meth)acrylates monomers, using a silylketeneacetal as initiator. ${ }^{52-54}$ In the present study, we compare the behavior of $\mathrm{Me}_{3} \mathrm{SiOTf}$ and $\mathrm{Me}_{3} \mathrm{SiNTf}_{2}$ as LA's when used in conjunction with different phosphines, including $\mathrm{P}^{t} \mathrm{Bu}_{3}, \mathrm{P}^{n} \mathrm{Bu}_{3}$ and TTMPP as LB's. Remarkably, the peculiar combination involving TTMPP:Me $\mathrm{SiNTf}_{2}$ in a 1:2 molar ratio allows the metal-free LPP being conducted at room temperature in toluene, providing poly(methyl methacrylate) (PMMA) chains controlled by the initial $[\mathrm{MMA}]_{0} /[\mathrm{TTMPP}]_{0}$ molar ratio. Both Density Functional Theory (DFT) calculations and stoichiometric reactions establish that a Psilyl phosphonium adduct results from the association of TTMPP and $\mathrm{Me}_{3} \mathrm{SiNTf}_{2}$. Yet, this adduct is found to be in equilibrium with the corresponding FLP as the true active form of the initiation step. Computational data also show that both initiation and propagation steps involve low activation barriers, in agreement with experimental observations, which overall support the existence of a dual/cooperative mechanism.

\section{EXPERIMENTAL}

\section{Materials.}

Toluene was refluxed over $\mathrm{CaH}_{2}$ and cryo-distilled from polystyryllithium (PS-Li) prior to use. Methyl methacrylate (MMA) was purchased from Sigma-Aldrich, degased, dried over $\mathrm{CaH}_{2}$, cryo-distilled into a burette and stored at $-20^{\circ} \mathrm{C}$. Trimethylsilyl trifluoromethanesulfonate $\left(\mathrm{Me}_{3} \mathrm{SiOTf}\right.$ ) and $\mathrm{N}$-trimethylsilylbis(trifluoromethane)sulfonimide $\left(\mathrm{Me}_{3} \mathrm{SiNTf}_{2}\right)$ were purchased from TCI Chemical and used as received. Tri- $n$ butylphosphine $\left(\mathrm{P}^{\mathrm{n}} \mathrm{Bu}_{3}\right)$ was purchased from Sigma Aldrich $(95 \%)$ and cryo-distilled. Tri-tert-butylphosphine $\left(\mathrm{P}^{t} \mathrm{Bu}_{3}\right)$ and tris(2,4,6-trimethoxyphenyl)phosphine (TTMPP) were purchased from Strem Chemical and Sigma Aldrich, respectively, and used as received. All Lewis acids and bases were kept under an argon glovebox.

\section{Methods.}

NMR spectra were recorded on a Bruker AC-400 spectrometer $\left({ }^{1} \mathrm{H},{ }^{13} \mathrm{C},{ }^{31} \mathrm{P},{ }^{29} \mathrm{Si}\right.$ of $400 \mathrm{MHz}, 100 \mathrm{MHz}$, $162 \mathrm{MHz}$ and $79.5 \mathrm{MHz}$, respectively) in appropriate deuterated solvents.

Molar masses of polymers samples were determined by size exclusion chromatography (SEC) using a set of PSS GRAM columns with pore sizes of $10 \mu \mathrm{m}$ (guard column), $30 \AA$ and $1000 \AA$ calibrated with narrow Polystyrene standards from Polymer Laboratories using both refractometric and UV detectors (Varian). DMF 
was used as eluent $\left(0.8 \mathrm{~mL} \cdot \mathrm{min}^{-1}\right)$ and toluene as a flow marker $(300 \mu \mathrm{L}$ toluene $/ 100 \mathrm{~mL} \mathrm{DMF})$ at $50^{\circ} \mathrm{C}$, in the presence of $\operatorname{LiBr}\left(2.17 \mathrm{~g} . \mathrm{L}^{-1}\right)$.

MALDI-ToF experiments were performed by the ISM-CESAMO (Bordeaux, France) on a Voyager mass spectrometer (Applied Biosystems). The instrument is equipped with a pulsed $\mathrm{N}_{2}$ laser $(337 \mathrm{~nm})$ and a timedelayed extracted ion source. Spectra were recorded in the positive-ion mode using the reflectron and with an accelerating voltage of $20 \mathrm{kV}$. Samples were dissolved in THF at $10 \mathrm{mg} / \mathrm{ml}$. The IAA matrix (trans-3Indoleacrylic acid) solution was prepared by dissolving $10 \mathrm{mg}$ in $1 \mathrm{ml}$ of THF. A MeOH solution of cationization agent $(\mathrm{NaI}, 10 \mathrm{mg} / \mathrm{ml})$ was also prepared. The solutions were combined in a 10:1:1 volume ratio of matrix to sample to cationization agent. One to two microliters of the obtained solution was deposited onto the sample target and vacuum-dried.

\section{Lewis pair polymerization of methyl methacrylate.}

All polymerization experiments were performed under a dry and inert atmosphere using Schlenk techniques. In a typical procedure, $50 \mu \mathrm{L}(216 \mu \mathrm{mol})$ of $\mathrm{Me}_{3} \mathrm{SiNTf}_{2}$ and $0.5 \mathrm{~mL}(4.7 \mathrm{mmol})$ of MMA were dissolved in $3 \mathrm{~mL}$ of toluene in a flame-dried Schlenk flask in the glovebox. A 3mL toluene solution of $58 \mathrm{mg}(108 \mu \mathrm{mol})$ of TTMPP was added dropwise on the solution of MMA-TMSNTf $f_{2}$. After $2 \mathrm{~h}$ at $25^{\circ} \mathrm{C}$, an aliquot of the polymerization mixture was taken to determine the conversion by ${ }^{1} \mathrm{H} \mathrm{NMR}$ analysis in $\mathrm{CDCl}_{3}$ and the reaction was quenched at the air. Volatiles were removed under vacuum. The crude product was re-dissolved in toluene and precipitated in methanol twice. After drying under vacuum, PMMA was recovered as a white solid.

\section{Chain extension experiments.}

In a typical experiment, $0.5 \mathrm{~mL}$ of MMA (43 eq. relative to TTMPP) was added onto the living PMMA chain obtained after $5 \mathrm{~h}$ (run 1, $98 \%$ of conversion). After $15 \mathrm{~h}, 100 \%$ of MMA conversion was reached (check by ${ }^{1} \mathrm{H}$ NMR; run 2). An addition load of $1 \mathrm{~mL}$ of MMA was again added (run 3). After 24h of reaction, $100 \%$ of conversion was achieved and the work-up was the same as that described above.

\section{Model reactions.}

Equimolar reactions between TTMPP and TMSNTf 2 and MMA and $\mathrm{TMSNTf}_{2}$ were performed in a J-Young NMR tube and monitored by ${ }^{1} \mathrm{H},{ }^{13} \mathrm{C},{ }^{31} \mathrm{P}$ and ${ }^{29} \mathrm{Si}$ NMR spectroscopies. In a typical procedure, $10 \mu \mathrm{L}(43 \mu \mathrm{mol})$ of $\mathrm{Me}_{3} \mathrm{SiNTf}_{2}$ and $23.1 \mathrm{mg}$ ( $\left.43 \mu \mathrm{mol}\right)$ of TTMPP or $5 \mu \mathrm{L}$ ( $\left.43 \mu \mathrm{mol}\right)$ of MMA were dissolved in $0.6 \mathrm{~mL}$ of dried toluene- $d_{8}$ (or bromobenzene- $d_{5}$ ) in a J-Young NMR tube in the glovebox.

\section{COMPUTATIONAL DETAILS}

Optimizations were carried out with the Gaussian 09 program $^{55}$ at the DFT level of theory using the M06-2X functional. ${ }^{56}$ All the different atoms (C, N, H, O, F, Si, P and $\mathrm{S}$ ) have been described with a 6$31 \mathrm{G}(\mathrm{d}, \mathrm{p})$ double- $\zeta$ basis set. ${ }^{57}$ Geometry optimizations were carried out without any symmetry restrictions in the gas phase. The nature of the extrema, minima or transition states, was verified with analytical frequency calculations, by the absence or presence of only one negative eigenvalue, respectively. The connection between the transition states and the corresponding minima was confirmed by IRC calculations. ${ }^{58,59}$ Single-point energies were performed on fully optimized geometries in gas phase, taking into account the solvent effect, toluene $(\varepsilon=2.3741)$, as a uniform polarizable medium with a dielectric constant using SMD model ${ }^{60}$ with M06$2 \mathrm{X}$ (SMD-toluene)/6-311++G(2d,2p) level of theory. Entropic effects were not included since they tend to overestimate the energetic costs of multi-molecular ( 3 molecules in our study) processes.

The electron density of FLP (5) and preorganized complex between TTMPP and activated-MMA was subjected to an Atoms-In-Molecules analysis (QTAIM analysis) ${ }^{61-62}$ using AIMAll software. ${ }^{63}$ Natural Bond Orbital $^{64-66}$ analysis (NBO) was also performed in order to identify the presence or not of stabilizing orbital interactions (NBO-3.1 implemented in Gaussian).

${ }^{31}$ P-NMR chemical shifts were evaluated by employing the direct implementation of the Gauge Including Atomic Orbitals (GIAO) ${ }^{67,68}$ method at the M06-2X density functional level of theory with IGLOO$\mathrm{II}^{69}$ basis set $\left(\mathrm{H}_{3} \mathrm{PO}_{4}\right.$ as a reference) using previously optimized gas phase structures at the M06-2X/6-31G** level (M06-2X/IGLO-II//M06-2X/6-31G**). 


\section{RESULTS AND DISCUSSION}

We turned to phosphines as nucleophilic components of Lewis pairs (LP's), because we anticipated that the interaction between the phosphorus-containing LB and the silane LA would be weaker than in the case of NHCs as nucleophiles. In the latter case, indeed, $\mathrm{C}_{2}$ - and $\mathrm{C}_{4}$-trimethylsilyl covalent (and irreversible) adducts have been evidenced. ${ }^{70,71}$ Three commercially available phosphines were thus tested (Figure 1), namely, tri-tert-butylphosphine $\left(\mathrm{P}^{t} \mathrm{Bu}_{3}\right)$, tri- $n$-butylphosphine $\left(\mathrm{P}^{n} \mathrm{Bu}_{3}\right)$ and tris-(2,4,6-trimethoxyphenyl)phosphine (TTMPP). Both $\mathrm{Me}_{3} \mathrm{SiNTf}_{2}$ and $\mathrm{Me}_{3} \mathrm{SiOTf}$ were assessed, knowing that the latter LA is less active. ${ }^{45}$ Moreover, given the coordinating character of the selected silanes and the well-established reactivity of phosphines toward chlorinated solvents, such as dichloromethane or chloroform ${ }^{69}$, only toluene was here considered as a non-oxygenated and non-chlorinated solvent.
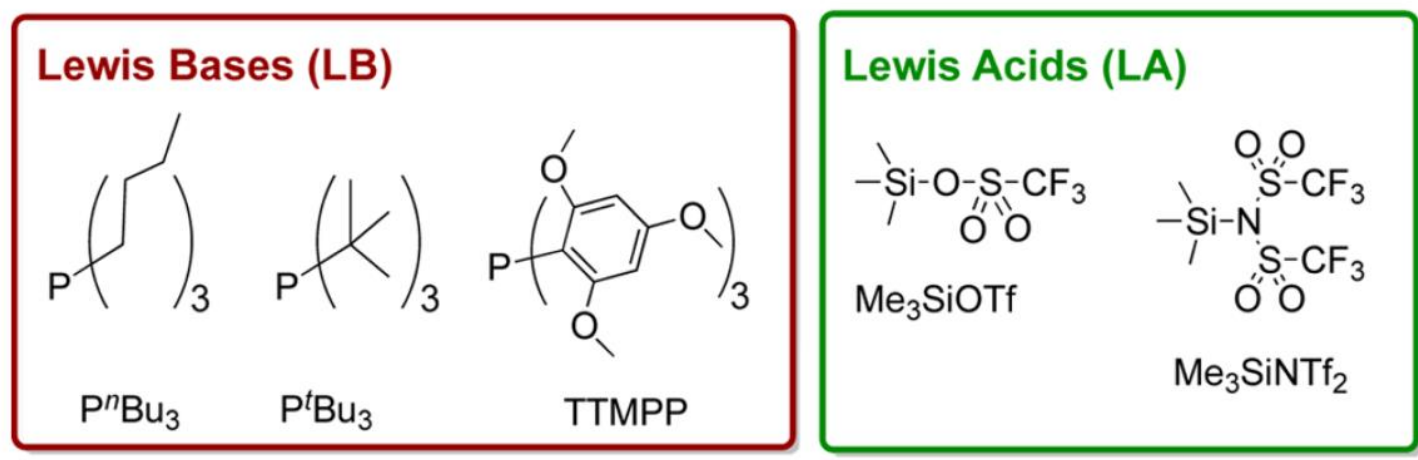

Figure 1. Phosphines and silanes used in this work as Lewis bases and Lewis acids, respectively.

\section{1- Screening of the Lewis pairs and further investigation into MMA polymerization}

Initial screening revealed that no polymerization of MMA occurred even after $48 \mathrm{~h}$ when using the Lewis acid $\left(\mathrm{Me}_{3} \mathrm{SiOTf}\right.$ or $\left.\mathrm{Me}_{3} \mathrm{SiNTf}_{2}\right)$ or the phosphine $\left(\mathrm{P}^{\prime} \mathrm{Bu}_{3}\right.$ or $\mathrm{P}^{\mathrm{n}} \mathrm{Bu}_{3}$ or TTMPP) alone (Table 1, entries 12). Attempts to polymerize MMA using $\mathrm{Me}_{3} \mathrm{SiNTf}_{2}$ and TTMPP in a 1:1 or 0.5:1 ratio were also unsuccessful (entries 6-7). In contrast, MMA could be readily polymerized when using any of the three phosphines in conjunction with $\mathrm{Me}_{3} \mathrm{SiNTf}_{2}$ in a 1:2 ratio (entries 3-5 and 8; see also Scheme 1). Complete MMA conversion was achieved within 3-15 h, in toluene at $25^{\circ} \mathrm{C}$ (Table 1, entries 3-5 for $\mathrm{P}^{t} \mathrm{Bu}_{3}, \mathrm{P}^{n} \mathrm{Bu}_{3}$ and TTMPP, respectively), suggesting that a cooperative activation of the monomer was certainly operative under those conditions. No polymerization was observed using the less electrophilic $\mathrm{Me}_{3} \mathrm{SiOTf}$ in presence of any of the phosphine (Table 1, entry 9), highlighting the selective character of the silane component $\left(\mathrm{Me}_{3} \mathrm{SiNTf}_{2} v s\right.$. $\left.\mathrm{Me}_{3} \mathrm{SiOTf}\right)$.
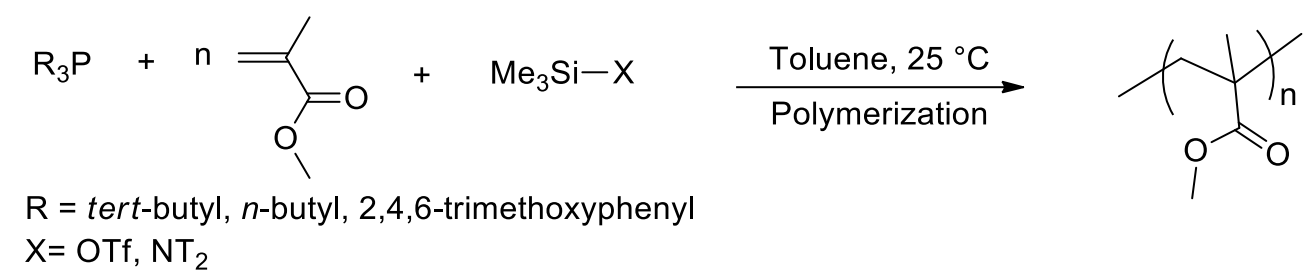

Scheme 1. Polymerization of MMA at $25^{\circ} \mathrm{C}$ in toluene using a phosphine in conjunction with a silane.

These preliminary phosphine/Me $\mathrm{MiNTf}_{2}$-induced LPP experiments also showed a good agreement between experimental molecular weights, as determined by ${ }^{1} \mathrm{H}$ NMR analysis, and values deduced from the initial $[\mathrm{MMA}]_{0} /[\mathrm{LB}]_{0}$ molar ratio, regardless of the nature of the phosphine. In addition, low dispersity values, as obtained by SEC analysis, supported the occurrence of a controlled polymerization $(\nexists<1.10)$. As illustrated in Figure 2, both refractometric (RI) and UV $\left(\lambda_{\max }=260 \mathrm{~nm}\right)$ signals of SEC traces of TTMPP-derived PMMA proved superimposable further evidencing the presence of the aromatic phosphine at the PMMA chain ends. Given the similar reactivity of the three phosphines under those conditions, TTMPP was selected for further investigations of the LPP of MMA, due to the NMR and SEC-UV handles provided by the aromatic groups attached to the phosphorus center of this phosphine. 
Table 1. Polymerization of MMA at $25^{\circ} \mathrm{C}$ in toluene in presence of a phosphine and $\mathrm{Me}_{3} \mathrm{SiNTf}_{2}$ or $\mathrm{Me}_{3} \mathrm{SiOTf}_{2}$

\begin{tabular}{|c|c|c|c|c|c|c|c|c|c|}
\hline Entry & $\mathbf{L A}$ & LB & $\begin{array}{c}{[\mathbf{M M A}]_{0} /[\mathbf{L A}]_{0}} \\
/[\mathbf{L B}]_{0}\end{array}$ & $\begin{array}{c}\text { Time } \\
\text { (h) }\end{array}$ & $\begin{array}{l}\text { Conv. } \\
\text { a) }(\%)\end{array}$ & $\begin{array}{l}\bar{M}_{n} \text { theo b) } \\
\left(\text { g.mol}^{-1}\right)\end{array}$ & $\begin{array}{l}\left.\bar{M}_{n} \text { NMR c }\right) \\
\left(\text { g.mol }{ }^{-1}\right)\end{array}$ & 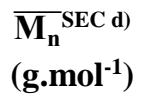 & $\boldsymbol{\oplus}^{\mathbf{d})}$ \\
\hline 1 & $\mathrm{Me}_{3} \mathrm{SiX}$ & - & $43 / 2 /-$ & 48 & 0 & - & - & - & - \\
\hline 2 & - & $\mathrm{PR}_{3}$ & $43 /-/ 1$ & 48 & 0 & - & - & - & - \\
\hline 3 & $\mathrm{Me}_{3} \mathrm{SiNTf}_{2}$ & $\mathrm{P}^{t} \mathrm{Bu}_{3}$ & $43 / 2 / 1$ & 7 & 100 & 4,500 & 6,800 & 13,700 & 1.06 \\
\hline 4 & $\mathrm{Me}_{3} \mathrm{SiNTf}_{2}$ & $\mathrm{P}^{n} \mathrm{Bu}_{3}$ & $43 / 2 / 1$ & 15 & 100 & 4,400 & n.d. & 8,700 & 1.03 \\
\hline 5 & $\mathrm{Me}_{3} \mathrm{SiNTf}_{2}$ & TTMPP & $43 / 2 / 1$ & 3 & 100 & 4,300 & 6,700 & 7,500 & 1.08 \\
\hline 6 & $\mathrm{Me}_{3} \mathrm{SiNTf}_{2}$ & TTMPP & $86 / 0.5 / 1$ & 24 & 0 & - & - & - & - \\
\hline 7 & $\mathrm{Me}_{3} \mathrm{SiNTf}_{2}$ & TTMPP & $86 / 1 / 1$ & 24 & 0 & - & - & - & - \\
\hline 8 & $\mathrm{Me}_{3} \mathrm{SiNTf}_{2}$ & TTMPP & $86 / 2 / 1$ & 3 & 100 & 8,600 & 8,900 & 13,100 & 1.07 \\
\hline 9 & $\mathrm{Me}_{3} \mathrm{SiOTf}$ & $\mathrm{PR}_{3}$ & $43 / 2 / 1$ & 48 & 0 & - & - & - & \\
\hline
\end{tabular}

a) Conv. $=\%$ monomer conversion determined by ${ }^{1} \mathrm{H}$ NMR spectroscopy. ${ }^{\text {b) }}$ Theoretical molecular weight $\overline{\mathrm{M}}_{\mathrm{n}}^{\text {theo }}=$ $\mathrm{M}_{\mathrm{LB}}+\mathrm{M}_{\mathrm{MMA}} \times \frac{[\mathrm{MMA}]}{[\mathrm{LB}]} \times \mathrm{conv}$. ${ }^{\mathrm{c})}$ Molecular weight $\overline{\mathrm{M}}_{\mathrm{n}}$ determined by ${ }^{1} \mathrm{H}$ NMR based on integration of characteristic protons of the phosphines. ${ }^{\text {d) }}$ Determined by SEC in DMF, using PS standards.

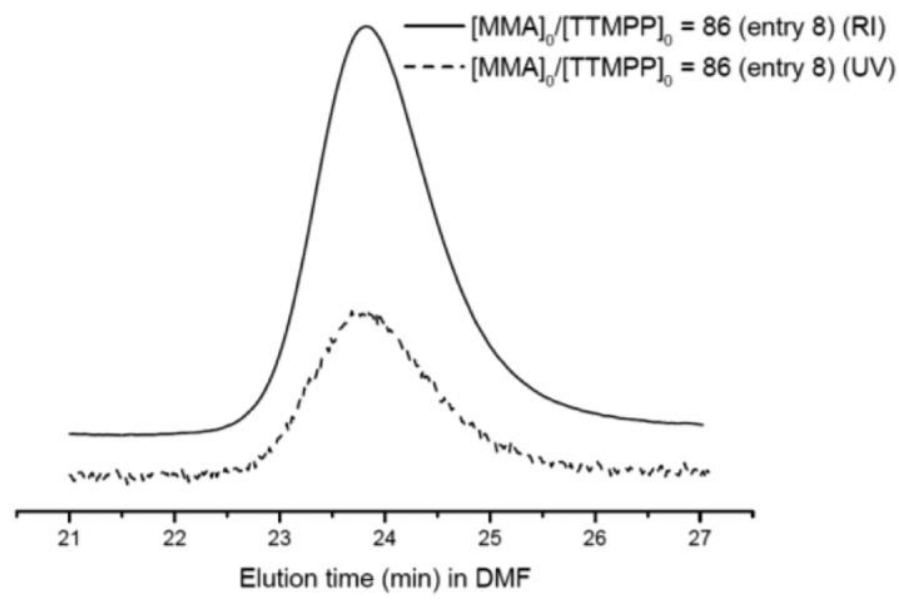

Figure 2. SEC traces (RI-UV $260 \mathrm{~nm}$ ) of PMMA obtained using TTMPP/TMSNTf $2(1 / 2)$ in toluene at $25^{\circ} \mathrm{C}\left(\mathrm{Table}^{1}\right.$, entry 8).

The absence of polymerization for experiments with $\mathrm{Me}_{3} \mathrm{SiNTf}_{2} / \mathrm{TTMPP}$ ratios equal to 0.5 and 1 (Table 1, entries 6-7) are reminiscent to observations by Chen et al. regarding the direct LPP of MMA by a $\mathrm{LB} / \mathrm{Al}\left(\mathrm{C}_{6} \mathrm{~F}_{5}\right)_{3}\left(\mathrm{LB}=t \mathrm{Bu}_{3} \mathrm{P}, \mathrm{Ph}_{3} \mathrm{P}\right.$ or IMes). ${ }^{11,32-34}$ Polymerization mechanism indeed involves a first equivalent of LA to activate MMA toward the 1,4-conjugate addition reaction of the LB (initiation step), while another equivalent is required for the activation of a second molecule of MMA, allowing thus the phosphonium enolaluminate growing species to add in a 1,4-fashion onto this activated monomer (scheme 2). By analogy with this "bimetallic mechanism", two equivalents of $\mathrm{Me}_{3} \mathrm{SiNTf}_{2}$ were also required in the present study, to activate a first equivalent of MMA in the initiation step (in green, scheme 2) and a second equivalent in the propagation step (in blue, scheme 2). Thus, conjugated addition of the phosphine onto $\mathrm{Me}_{3} \mathrm{SiNTf}_{2}$-activated MMA likely yielded a $\alpha$-phosphonium silyl ketene acetal ( $\alpha$-PSKA) ion pair, rather than a zwitterionic-type intermediate LA-stabilized enolate as observed with the LB/Al system (scheme 2). ${ }^{11,32-34}$ Propagation would

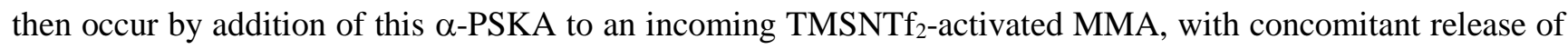
one equivalent of $\mathrm{TMSNTf}_{2}$. Finally, the experimentally observed $\alpha$-phosphonium, $\omega$-H PMMA would result from the hydrolysis of the SKA moiety under air exposure. It is noteworthy that these SKA-type growing chain ends are very similar to those characterizing the group transfer polymerization (GTP) of MMA.41-44,73-76 


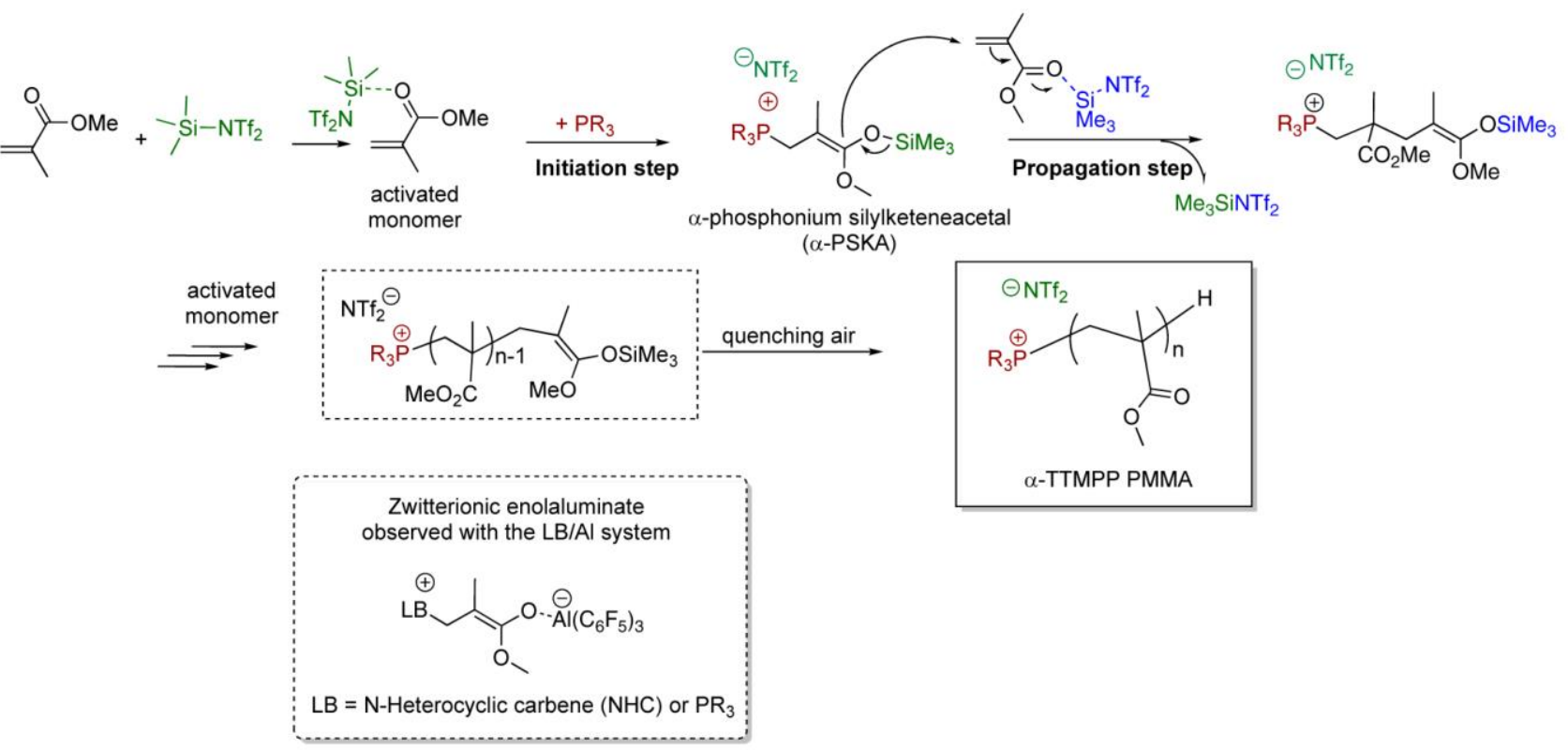

Scheme 2. Proposed mechanism for the LPP of MMA using the TTMPP/Me $\operatorname{SiNTf}_{2}(1 / 2)$.

A typical ${ }^{1} \mathrm{H}$ NMR spectrum of a purified TTMPP/Me $3 \mathrm{SiNTf}_{2}$-derived PMMA is shown in Figure 3. Characteristic protons due to methoxy and aromatic groups at $\delta_{\mathrm{OCH} 3}=3.83 \mathrm{ppm}$ and $\delta_{\text {aromatic }}=6.04 \mathrm{ppm}$, respectively, revealed the presence of a phosphine moiety in $\alpha$-position, derived from TTMPP. Relative integration of methyl, methylene and methoxy protons from MMA units $\left(\delta_{\mathrm{CH} 3}=0.8 \mathrm{ppm}, \delta_{\mathrm{CH} 2}=1.77 \mathrm{ppm}\right.$ and $\delta_{\mathrm{OCH} 3}=3.56 \mathrm{ppm}$, respectively) with that due to methine protons of the phosphine $\left(\delta_{\mathrm{CH} 2}=6.06 \mathrm{ppm}\right.$; Figure $\mathrm{S} 1$ ), allowed us to determine the PMMA molar mass. This calculation was based on the assumption that chain ends were either in the form of linear $\mathrm{R}_{3} \mathrm{P}(+)-\mathrm{PMMA}-\mathrm{H}$ structure $\left(\mathrm{A}_{1}\right.$ in Scheme 3$)$ or as neutral cyclic structure, as the result of a cyclization involving the reaction of the enolate end with the phosphorus center (B in Scheme 3). The molar mass thus determined was slightly higher than the theoretical value based on the initial ratio $[\mathrm{MMA}]_{0} /[\mathrm{TTMPP}]_{0}\left(\overline{\mathrm{M}}_{\mathrm{n}}{ }^{\text {theo }}=8,600 \mathrm{~g} \cdot \mathrm{mol}^{-1}\right.$ vs. ${\overline{\mathrm{M}_{\mathrm{n}}}}^{\mathrm{NMR}}=8,900 \mathrm{~g} \cdot \mathrm{mol}^{-1}$; Table 1 , entry 8$)$, presumably due to the hydrolysis of $\mathrm{Me}_{3} \mathrm{SiNTf}_{2}$ by residual water in the system (see discussion below).

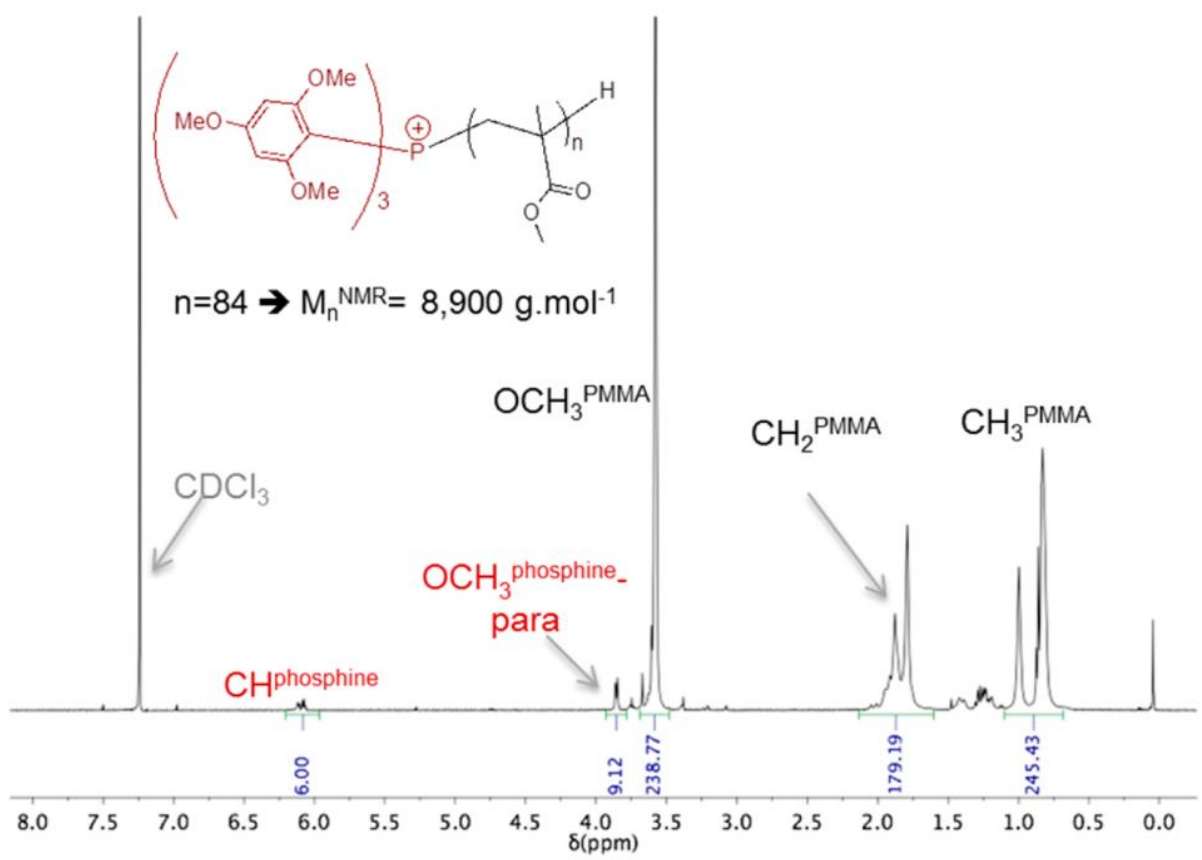

Figure 3. ${ }^{1} \mathrm{H}$ NMR spectrum in $\mathrm{CDCl}_{3}$ of PMMA obtained using TTMPP/TMSNTf $2(1 / 2)$ in toluene at $25{ }^{\circ} \mathrm{C}($ Table 1 , entry 8) 

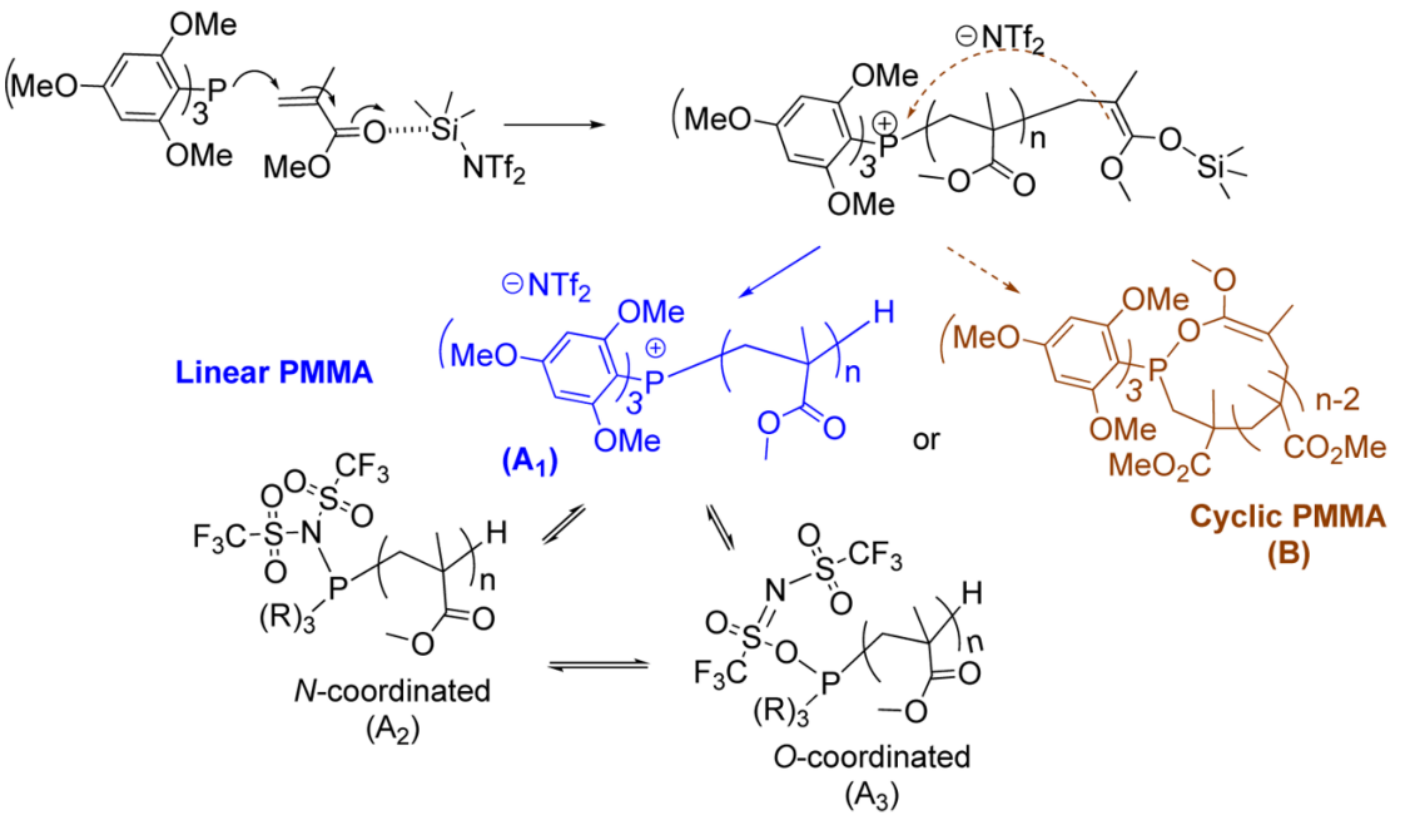

Scheme 3. Proposed mechanism for the formation of phosphonium- and neutral phosphorane $\left(\mathrm{P}^{\mathrm{V}}\right)$-terminated PMMA's.

The tacticity of this TTMPP/Me $\mathrm{SiNTf}_{2}$-derived PMMA was also evaluated based on the signals from $\mathrm{CH}_{3}$ groups (ESI, Figure S3).77 The result was as follows: syndiotacticity (\% of triad rr) $=62 \%$, heterotacticity $(\%$ of triad $\mathrm{mr})=34 \%$ and isotacticity $(\%$ of triad $\mathrm{mm})=4 \%$. This tacticity is somewhat comparable to that observed in the $\mathrm{Me}_{3} \mathrm{SiNTf}_{2}$-catalyzed GTP of MMA with a SKA initiator $\left(\% \mathrm{rr} / \mathrm{mr} / \mathrm{mm}=72 / 27 / 1\right.$ at $25^{\circ} \mathrm{C}$ in $\left.\mathrm{CH}_{2} \mathrm{Cl}_{2}\right) .{ }^{52,53}$

Characterization by ${ }^{31} \mathrm{P}$ NMR (Figure 4) eventually revealed the presence of two main signals in a 73:19 ratio, at 2.4 and $2.9 \mathrm{ppm}$, strongly shifted downfield compared to that of free TTMPP $(\delta=-71.8 \mathrm{ppm}$ in toluene- $d_{8}$; see also Figure S2). Given the very similar chemical shifts, these species probably corresponded to $\alpha$-phosphonium PMMA's of different microstructures. Although we could not attribute each observed signal, one of the populations might correspond to the expected $\alpha$-phosphonium PMMA chains (linear $\mathrm{A}_{1}$ or cyclic B in Scheme 2). However, the presence of species coordinated to the triflimide anion could also be considered (Species $A_{2}$ and $A_{3}$, Scheme 3), although the equilibrium highly favors the formation of a non-coordinated phosphonium $\left(\mathrm{A}_{1}\right)$. Besides those signals, the doublet at $-52.8 \mathrm{ppm}$ could unambiguously be attributed to the TTMPP-H phosphonium salt, i.e. featuring a direct P-H bond, owing to the large ${ }^{1} \mathrm{~J}_{\mathrm{PH}}$ coupling constant $\left({ }^{1} \mathrm{~J}_{\mathrm{PH}}=\right.$ $535 \mathrm{~Hz}$ ). This compound most likely arose from the protonation of the phosphine by $\mathrm{HNTf}_{2}$, resulting from the hydrolysis of $\mathrm{Me}_{3} \mathrm{SiNTf}_{2}$ by adventitious water (Scheme 4). According to ${ }^{31} \mathrm{P} \mathrm{NMR}$, this side reaction led to the formation of $7 \%$ of phosphonium salt. This also explained the slightly higher molecular weights noted (Table 1), a small part of the phosphine [TTMPP $]_{0}$ being not available for initiation.

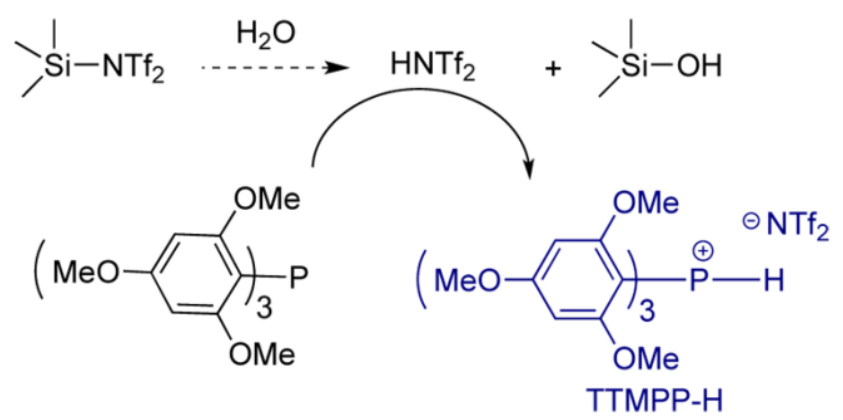

Scheme 4. Protonation of the phosphine resulting from the presence of adventitious water. 


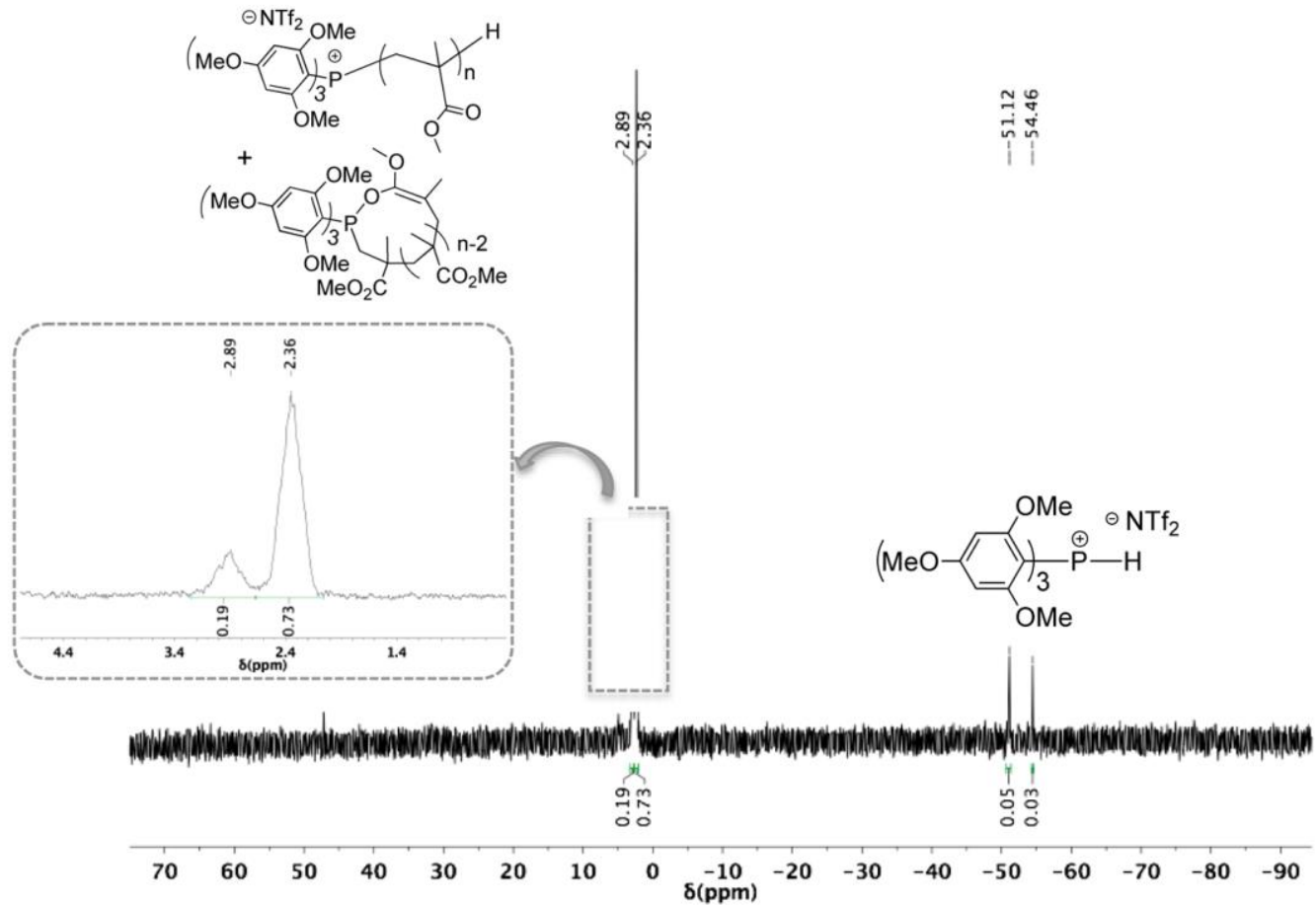

Figure 4. ${ }^{1} \mathrm{H}$ coupled- ${ }^{31} \mathrm{P}$ NMR spectrum in $\mathrm{CDCl}_{3}$ of $\mathrm{PMMA}$ obtained using $\mathrm{TTMPP} / \mathrm{Me}_{3} \mathrm{SiNTf}_{2}(1 / 2)$ in toluene at $25{ }^{\circ} \mathrm{C}$

(Table 1, Table 1, entry 8 ).

Analysis by MALDI-ToF mass spectrometry of the same PMMA revealed the presence of one main population (Figure 5). The corresponding series of peaks was ascribed to the targeted $\alpha$-phosphonium, $\omega-\mathrm{H}$ PMMA with $\mathrm{m} / \mathrm{z}=533.19+100.05 \mathrm{n}$, where 533.19 is the molar mass of the phosphonium and H-end-groups. However, as already described above, both the linear $\alpha$-phosphonium, $\omega-\mathrm{H}$ PMMA and the cyclic $\alpha$-phospholane PMMA structures having the same $\mathrm{m} / \mathrm{z}$, they could not de distinguished by MALDI ToF MS.
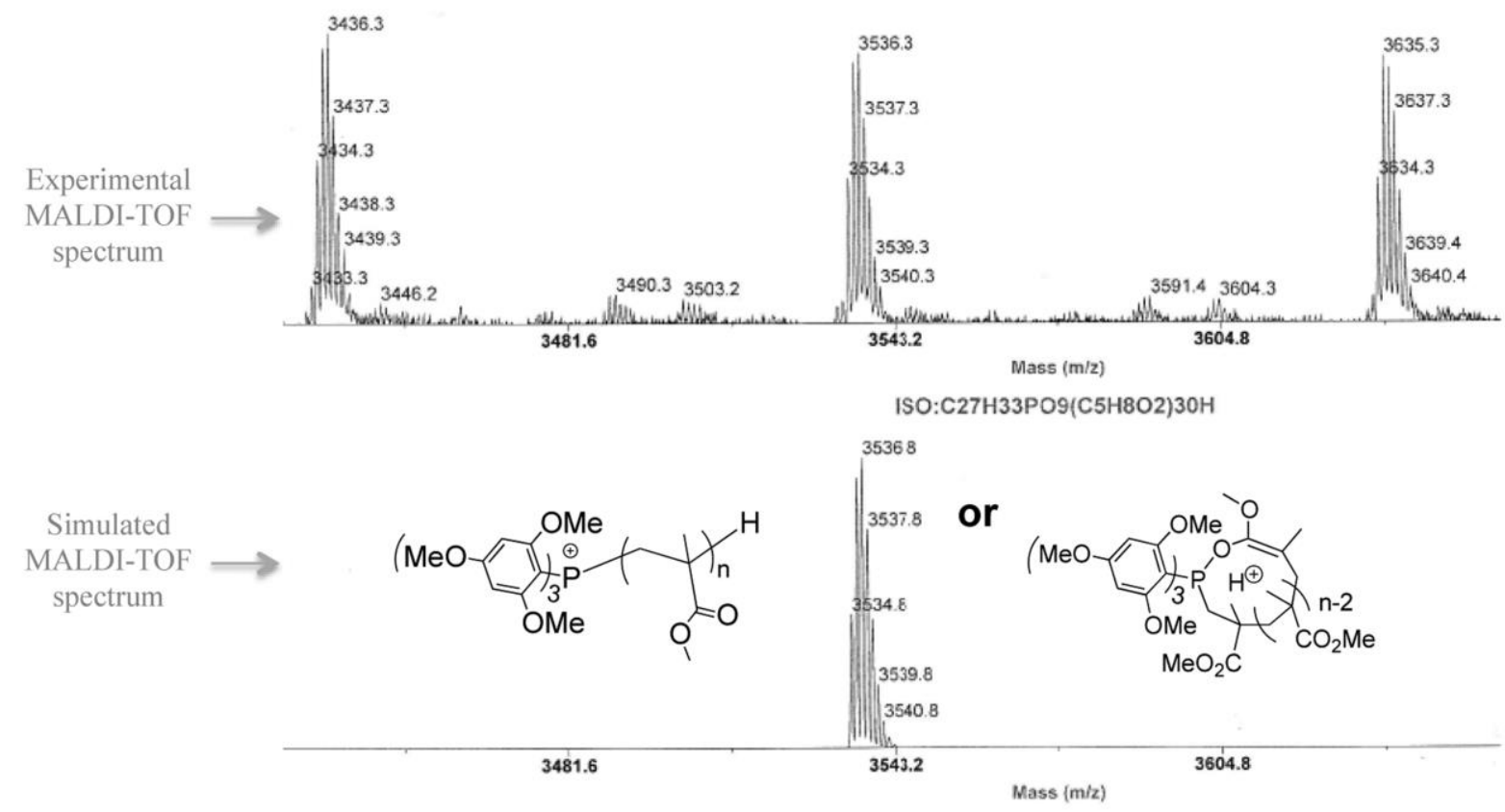

Figure 5. MALDI-ToF mass spectrum of PMMA synthesized from TTMPP/ $\mathrm{Me}_{3} \mathrm{SiNTf}_{2}(1 / 2)$ in toluene at $25^{\circ} \mathrm{C}(\mathrm{Table}$ 1 , entry 8).

The effect of the concentration in MMA was next investigated, using initial concentrations of [TTMPP $]_{0}$ $=18 \mathrm{mM}$ and $\left[\mathrm{TMSNTf}_{2}\right]_{0}=36 \mathrm{mM}$ (Table 2). For these experiments, a TTMPP solution was added onto a solution of MMA activated by TMSNTf 2 , keeping the LA/LB ratio equal to 2 . 
Table 2. Polymerization of MMA at $25^{\circ} \mathrm{C}$ in toluene using different $[\mathrm{MMA}]_{0} /\left[\mathrm{Me}_{3} \mathrm{SiNTf}_{2}\right]_{0} /[\mathrm{TTMPP}]_{0}$ ratios

\begin{tabular}{|c|c|c|c|c|c|c|c|c|}
\hline Entry & $\begin{array}{c}{\left[\mathrm{MMA}_{0} /\right.} \\
{\left[\mathrm{Me}_{3} \mathrm{SiNT}_{2}\right]_{0} /} \\
{[\mathrm{TTMPP}]_{0}}\end{array}$ & $\begin{array}{l}\text { Time } \\
\text { (h) }\end{array}$ & $\begin{array}{c}\text { Conv. a) } \\
(\%)\end{array}$ & $\begin{array}{l}\left.{\overline{M_{n}}}_{\text {theo }}{ }^{b}\right) \\
\left(\text { g.mol }^{-1}\right)\end{array}$ & $\begin{array}{l}\left.\overline{\mathrm{M}}_{\mathrm{n}} \mathrm{NMR}^{\mathrm{c}}\right) \\
\left(\mathrm{g} \cdot \mathrm{mol}^{-1}\right)\end{array}$ & $\begin{array}{l}\left.\overline{\mathrm{M}}_{\mathrm{n}} \mathrm{SEC}^{\mathrm{d}}\right) \\
\left(\mathrm{g} \cdot \mathrm{mol}^{-1}\right)\end{array}$ & $\begin{array}{l}\mathbf{M}_{\mathrm{pSEC}} \mathrm{d}^{-1} \\
\left(\mathrm{~g} \cdot \mathrm{mol}^{-1}\right)\end{array}$ & $\boldsymbol{D}^{\mathrm{d})}$ \\
\hline 1 & $43 / 2 / 1$ & 3 & 100 & 4,300 & 6,700 & 7,500 & 7,800 & 1.08 \\
\hline 2 & $86 / 2 / 1$ & 15 & 100 & 8,600 & 10,800 & 10,700 & 11,500 & 1.05 \\
\hline 3 & $172 / 2 / 1$ & 24 & 100 & 17,300 & 17,800 & 23,800 & 24,700 & 1.03 \\
\hline
\end{tabular}

a) Conv. $=\%$ monomer conversion determined by $1 \mathrm{H}$ NMR spectroscopy. ${ }^{\text {b) }}$ Theoretical molecular weight $\overline{\mathrm{M}}_{\mathrm{n}}^{\text {theo }}=$ $\mathrm{M}_{\mathrm{LB}}+\mathrm{M}_{\mathrm{MMA}} \times \frac{[\mathrm{MMA}]}{[\mathrm{LB}]} \times$ conv. ${ }^{\mathrm{c})} \overline{\mathrm{M}}_{\mathrm{n} \text { NMR }}$ determined by ${ }^{1} \mathrm{H}$ NMR based on integration of protons from TTMPP substituents. ${ }^{\text {d) }}$ Characterization by SEC in DMF using PS standards for calibration.

The TTMPP/Me $\mathrm{MiNTf}_{2}$-mediated LPP of MMA readily proceeded in toluene at $25{ }^{\circ} \mathrm{C}$, regardless of the initial $[\mathrm{MMA}]_{0}$, quantitative MMA conversion being achieved within $3 \mathrm{~h}$ (Table 2). According to ${ }^{1} \mathrm{H}$ NMR analysis, experimental molecular weights were again in rather good agreement with the expected values, based on the initial $[\mathrm{MMA}]_{0} /[\mathrm{TTMPP}]_{0}$ ratio, while dispersities remained narrow from SEC examination (Figure 6). These molar masses were found to increase with the monomer concentration $(0.94 \mathrm{M}, 1.88 \mathrm{M}$ and $3.76 \mathrm{M})$, leading to PMMA's with $\overline{\mathrm{M}}_{\mathrm{n}}{ }^{\mathrm{NMR}}$ values up to $17,800 \mathrm{~g} \cdot \mathrm{mol}^{-1}$.

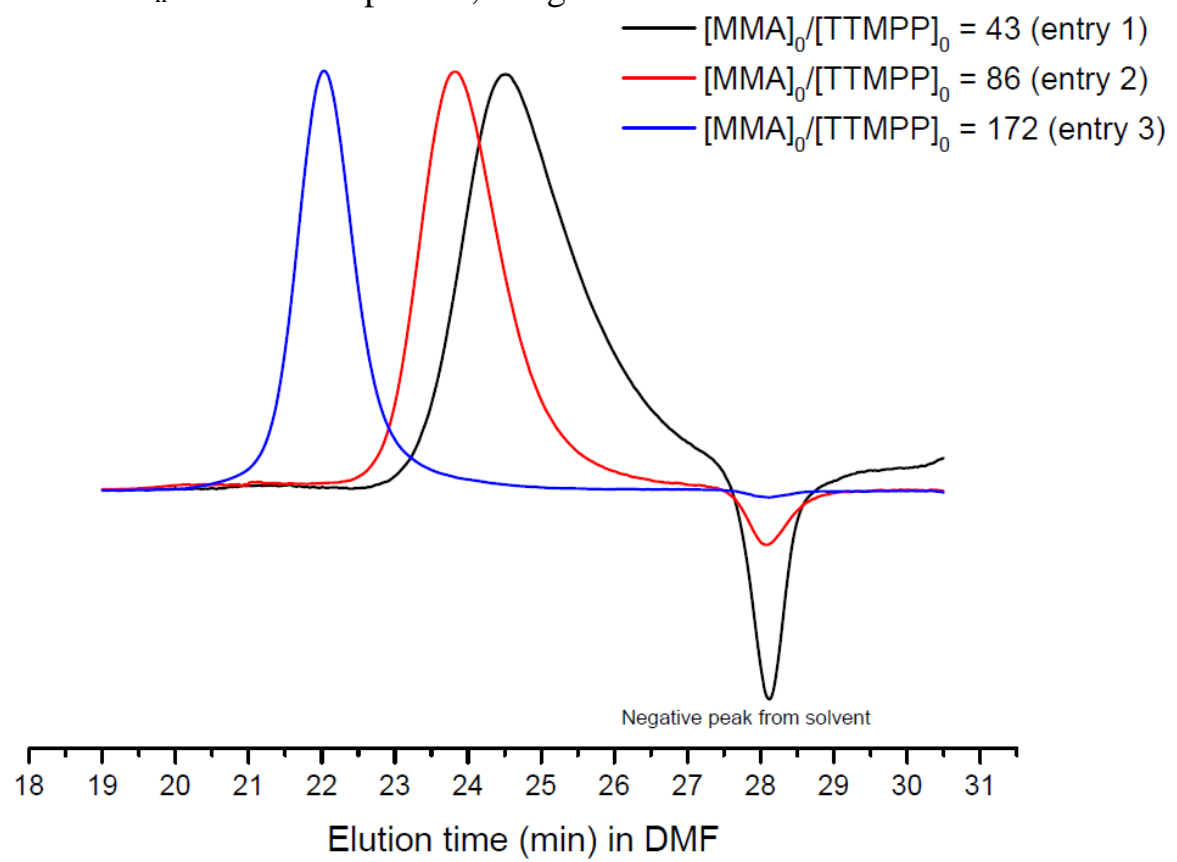

Figure 6. SEC-RI traces of PMMA's obtained with TTMPP/Me $\mathrm{SiNTf}_{2}(1 / 2)$ in toluene at $25{ }^{\circ} \mathrm{C}$ (Table 2).

Formation of narrowly distributed PMMA's thus attested to the occurrence of a controlled TTMPP/Me SiNTf $_{2}$-initiated LPP of MMA. These results thus contrast with those obtained by LPP of MMA utilizing a phosphine or a NHC as LB and aluminum-based LA's, where PMMA's of higher molecular weights values than those predicted by the initial $[\mathrm{MMA}]_{0} /[\mathrm{LB}]_{0}$ and of rather broad dispersity were observed. ${ }^{11,32-34}$ This might be ascribed to the weaker Lewis acidity of $\mathrm{Me}_{3} \mathrm{SiNTf}_{2}$ compared to $\mathrm{Al}\left(\mathrm{C}_{6} \mathrm{~F}_{5}\right)_{3}$, which presumably led to a weaker LB-LA interaction, thus allowing for an almost quantitative initiation by the phosphine in our case. However, the nature of the growing chain might also play a role: the aforementioned $\alpha$-PSKA (Scheme 4) might be less reactive and thus less prone to side reactions, than the aluminiumenolate growing species observed by Chen et al. ${ }^{11,32-34}$

The ability of the growing $\alpha$-PSKA-derived PMMA chains to be reactivated was also assessed. The LPP of MMA was first run in toluene at $25^{\circ} \mathrm{C}$ with initial concentrations: $[\mathrm{TTMPP}]_{0}=11 \mathrm{mM}$, $\left[\mathrm{Me}_{3} \mathrm{SiNTf}_{2}\right]_{0}=22 \mathrm{mM}$ and $[\mathrm{MMA}]_{0}=0.6 \mathrm{M}$ (Table 3, entry 1). After $5 \mathrm{~h}$ at $25{ }^{\circ} \mathrm{C}, 98 \%$ of monomer conversion was reached, producing a PMMA of molar mass $\overline{\mathrm{M}_{\mathrm{n}}}=7,500 \mathrm{~g} \cdot \mathrm{mol}^{-1}$ and dispersity $\doteq=1.08$. 
Adding a new load of 43 eq. of MMA (Table 3, entry 2) led to a PMMA of $\overline{\mathrm{M}_{\mathrm{n}}}=13,400 \mathrm{~g} \cdot \mathrm{mol}^{-1}(\nexists=1.07)$ after $15 \mathrm{~h}$ and full monomer conversion (entry 2). Another load of 86 eq. of MMA (Table 3, entry 3) was again added to the previous solution, yielding a new PMMA with a molecular weight of $31,000 \mathrm{~g} \cdot \mathrm{mol}^{-1}(\bigoplus=1.05)$ after complete monomer conversion $(24 \mathrm{~h})$. Resulting SEC traces of the different PMMA's obtained from these successive chain extension experiments are illustrated in Figure 7.

These results confirmed that phosphine/silane could promote a controlled LPP of MMA with a high endgroup fidelity, which could be ascribed to the presence of neutral and moderately reactive SKA chain ends, minimizing the occurrence of side reactions.

Table 3. Polymerization of MMA at $25^{\circ} \mathrm{C}$ in toluene for chain extension experiments

\begin{tabular}{|c|c|c|c|c|c|c|c|}
\hline Entry & $\begin{array}{c}{[\mathrm{MMA}]_{0} /\left[\mathrm{Me}_{3} \mathrm{SiNTf}_{2}\right]_{0} /} \\
{[\mathrm{TTMPP}]_{0}}\end{array}$ & $\begin{array}{l}\text { Time } \\
\text { (h) }\end{array}$ & $\begin{array}{c}\text { Conv. }{ }^{a)} \\
(\%)\end{array}$ & $\begin{array}{l}\bar{M}_{n} \text { theo b) } \\
\left(\text { g.mol}^{-1}\right)\end{array}$ & 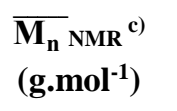 & $\begin{array}{l}{\overline{M_{n}}}_{\text {SEC }^{d}}{ }^{2} \\
\left(\text { g.mol }^{-1}\right)\end{array}$ & $\boldsymbol{D}^{\mathrm{c})}$ \\
\hline 1 & $43 / 2 / 1($ run 1$)$ & 5 & 98 & 4,750 & 4,750 & 7,500 & 1.08 \\
\hline 2 & run $1+43$ eq $($ run 2$)$ & 15 & 100 & 9,150 & 12,200 & 13,400 & 1.07 \\
\hline 3 & run $2+86$ eq $($ run 3$)$ & 24 & 100 & 17,750 & - & 31,000 & 1.05 \\
\hline
\end{tabular}

${ }^{\text {a) }}$ Conv. $=\%$ monomer conversion determined by ${ }^{1}$ H NMR spectroscopy. ${ }^{\text {b) }}$ Theoretical molecular weight $\overline{\mathrm{M}}_{\mathrm{n}}^{\text {theo }}=\mathrm{M}_{\mathrm{LB}}+\mathrm{M}_{\mathrm{MMA}} \times \frac{[\mathrm{MMA}]}{[\mathrm{LB}]} \times$ conv. ${ }^{\mathrm{c})} \overline{\mathrm{M}}_{\mathrm{n} \text { NMR }}$ determined by ${ }^{1} \mathrm{H}$ NMR based on integration of protons from TTMPP substituents. ${ }^{\text {d) }}$ Characterization of PMMA's by SEC in DMF using PS standards for calibration.

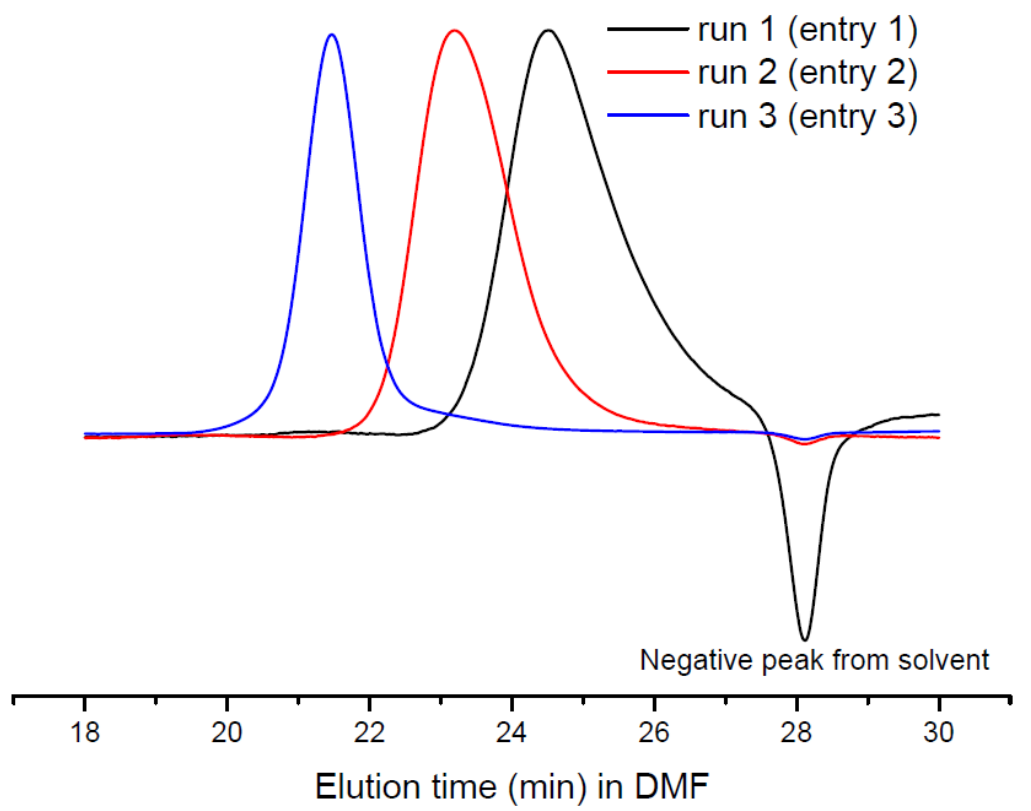

Figure 7. SEC-RI traces of PMMA obtained upon sequential addition of MMA onto TTMPP/TMSNTf ${ }_{2}$-derived living PMMA chains in toluene at $25^{\circ} \mathrm{C}$ (Table 3$)$.

\section{2- Stoichiometric studies: interaction of $\mathrm{Me}_{3} \mathrm{SiNTf}_{2}$ with MMA and TTMPP}

Model reactions involving the different polymerization components were performed to gain a better insight both into the type of LP formed when associating $\mathrm{Me}_{3} \mathrm{SiNTf}_{2}$ and TTMPP and into the activation mode of MMA. The reaction of TTMPP with 1 eq. of $\mathrm{Me}_{3} \mathrm{SiNTf}_{2}$ was first studied by ${ }^{31} \mathrm{P}$ NMR in toluene- $d_{8}$. After mixing the two LP reagents, however, a precipitate formed, precluding further characterization of the product. We thus turned to bromobenzene $\mathrm{PhBr}-d_{5}$, an inert and relatively polar solvent (compared to toluene). In this solvent, the signal corresponding to the free phosphine $(\delta=-67.2 \mathrm{ppm})$ vanished while a new signal at -34.2 ppm appeared, suggesting the formation of a P-Si bond (Figure S4). Unfortunately, no signal could be observed in the corresponding ${ }^{29} \mathrm{Si}$ NMR spectrum (Figure S5), making difficult the structural determination of the ensuing adduct. 
Depending on the interaction of the $\mathrm{NTf}_{2}$ anion with the silicon center, on one hand, and with the phosphorus center, on the other hand, different structures could yet be formulated; these are displayed in Figure 8. As already discussed above (Scheme 3), interaction of TTMPP with $\mathrm{Me}_{3} \mathrm{SiNTf}_{2}$ could form a cationic P-silyl phosphonium, $\mathbf{A}_{\mathbf{1}}$ ', or a neutral silyl- $N$-phosphorane, $\mathbf{A}_{\mathbf{2}}$ ', and its isomeric silyl- $O$-phosphorane, $\mathbf{A}_{\mathbf{3}}$ ', where $\mathrm{NTf}_{2}$ would be $N$ - and $O$-bound to the phosphorus center, respectively. The $\mathrm{NTf}_{2}$ anion could also remain in vicinity of the silicon atom and generate neutral phosphonium $N$-silicate and phosphonium $O$-silicate, denoted as $\mathbf{C}$ and $\mathbf{D}$, respectively. Although the hypervalency of silane is well-known, it requires several electronwithdrawing substituents to allow silicate formation. ${ }^{45}$ The formation of $\mathbf{C}$ and $\mathbf{D}$ thus appears unfavorable. Moreover, given the insolubility of the product in toluene, a cationic structure such as $\mathbf{A}_{\mathbf{1}}$ ' could be favored in a relatively polar solvent. The relative stability of all these compounds was also analyzed and confirmed by DFT calculation (see figure S14 and discussion in SI).

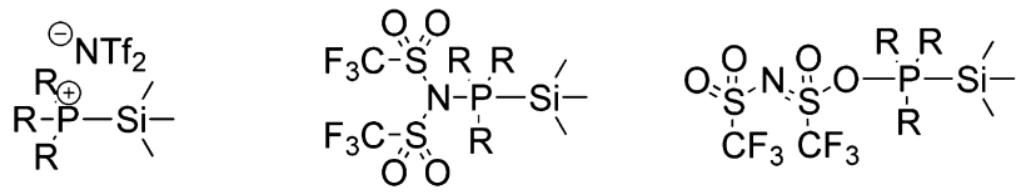

Silyl-phosphonium $\left(\mathbf{A}_{1}{ }^{\prime}\right) \quad$ Silyl-N-phosphorane $\left(\mathbf{A}_{\mathbf{2}}{ }^{\prime}\right) \quad$ Silyl-O-phosphorane $\left(\mathbf{A}_{3}{ }^{\prime}\right)$

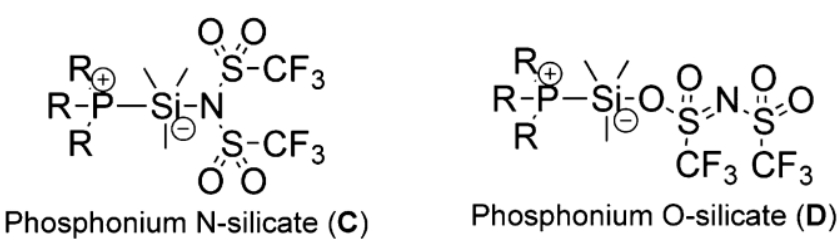

Figure 8. Possible interactions between the Lewis acid $\mathrm{Me}_{3} \mathrm{SiNTf}_{2}$ and the Lewis base TTMPP.

The presence of residual water in $\mathrm{PhBr}-d_{5}$ also forms the $\mathrm{P}-\mathrm{H}$ phosphonium $\left(\delta=-53.2 \mathrm{ppm}, \mathrm{d},{ }^{1} \mathrm{~J}_{\mathrm{PH}}=\right.$ $535 \mathrm{~Hz}$ ), as discussed in the case of LPP-derived PMMA's.

The ability of the silane to activate MMA was next investigated in toluene- $d_{8}$ by ${ }^{1} \mathrm{H},{ }^{13} \mathrm{C}$ and ${ }^{29} \mathrm{Si} \mathrm{NMR}$ (Figures S6-S8). Most significantly, in the ${ }^{1} \mathrm{H}$ NMR spectrum of the 1:1 $\mathrm{Me}_{3} \mathrm{SiNTf}_{2}: \mathrm{MMA}$ mixture (Figure S6), signals corresponding to $\mathrm{C}_{\beta} \mathrm{H}_{2}(\delta \mathrm{H}=5.23$ and $6.01 \mathrm{ppm})$ were downfield shifted by $0.20 \mathrm{ppm}$, relatively to free MMA $(\delta \mathrm{H}=5.03$ and $5.80 \mathrm{ppm})$. In parallel, signals attributed to $\mathrm{C}_{\beta}$ and $\mathrm{C}=\mathrm{O}$ carbons $\left(\delta \mathrm{C}_{\beta}=125.6 \mathrm{ppm}\right.$ and $\delta \mathrm{C}=\mathrm{O}=167.8 \mathrm{ppm}$ ), in the ${ }^{13} \mathrm{C}$ NMR spectrum of the stoichiometric mixture of $\mathrm{Me}_{3} \mathrm{SiNTf}_{2}$ and MMA (Figure S7), appeared at lower field than corresponding signals of MMA $\left(\delta \mathrm{C}_{\beta}=124.9 \mathrm{ppm}\right.$ and $\left.\delta_{\mathrm{C}=0}=167.2 \mathrm{ppm}\right)$. These data suggested a coordination of the silicon atom of $\mathrm{Me}_{3} \mathrm{SiNTf}_{2}$ to the carbonyl group of MMA, which in turn enhanced the electrophilicity of positions 2 and 4 . In ${ }^{29}$ Si NMR (Figure S8), the signal corresponding to the silicon center in $\mathrm{Me}_{3} \operatorname{SiNTf}_{2}\left(\delta_{\mathrm{Si}}=54.9 \mathrm{ppm}\right)$ was shifted upfield by $48 \mathrm{ppm}$ in the 1:1 mixture of $\mathrm{Me}_{3} \mathrm{SiNTf}_{2}$ and MMA $\left(\delta_{\mathrm{Si}}=7.1 \mathrm{ppm}\right)$, further attesting to the interaction between the two components. All these data are also in agreement with the formation of a tetravalent cationic silicon center, rather than of a hypervalent silicate species.

\section{3- Calculations by Density Functional Theory}

To gain a further insight into the role of TTMPP and $\mathrm{Me}_{3} \mathrm{SiNTf}_{2}$ in the course of MMA polymerization, DFT calculations were performed at the M06-2X(SMD-toluene)/6-311++G**//M06-2X/6-31G** level of theory, taking into account the solvent effect using SMD solvation model (toluene). $\mathrm{Me}_{3} \mathrm{SiNTf}_{2}$ was also compared to the less active $\mathrm{Me}_{3} \mathrm{SiOTf}$, which did not form any polymer when combined to TTMPP, in sharp contrast to $\mathrm{Me}_{3} \mathrm{SiNTf}_{2}$.

The ability of $\mathrm{Me}_{3} \mathrm{SiNTf}_{2}$ and $\mathrm{Me}_{3} \mathrm{SiOTf}$ to activate MMA was thus first studied computationally (Scheme 5). In both cases, both an activated and a non-activated form could be located on the potential energy surface (PES). The main structural difference between those two forms (Figures S9 and S10 in ESI for details) is related to the distance between the CO of MMA and the silicon center, a long O---Si distance ( $3.3 \AA$ ) being 
calculated for the non-activated form. In the case of the activated form, a cationic tetravalent silicon compound was computed, the anion being formally replaced by MMA. In the case of $\mathrm{Me}_{3} \mathrm{SiOTf}$, the rather large energetic difference calculated $(10 \mathrm{kcal} / \mathrm{mol}$ in favor of the non-activated species) between these two forms $(\mathbf{3}$ and $\mathbf{4}$, for the non-activated and activated form, respectively) suggested that $\mathrm{Me}_{3} \mathrm{SiOTf}$ was not electrophilic enough to activate MMA, as we also observed experimentally (no polymerization with this LA). In contrast, both structures ( $\mathbf{1}$ and $\mathbf{2}$, for the non-activated and activated form, respectively) were found almost isoenergetic in the case of $\mathrm{Me}_{3} \mathrm{SiNTf}_{2}$, indicating that the two forms were in equilibrium. Overall, these data strongly supported that only $\mathrm{Me}_{3} \mathrm{SiNTf}_{2}$ was able to activate MMA, consistently with experimental observations.

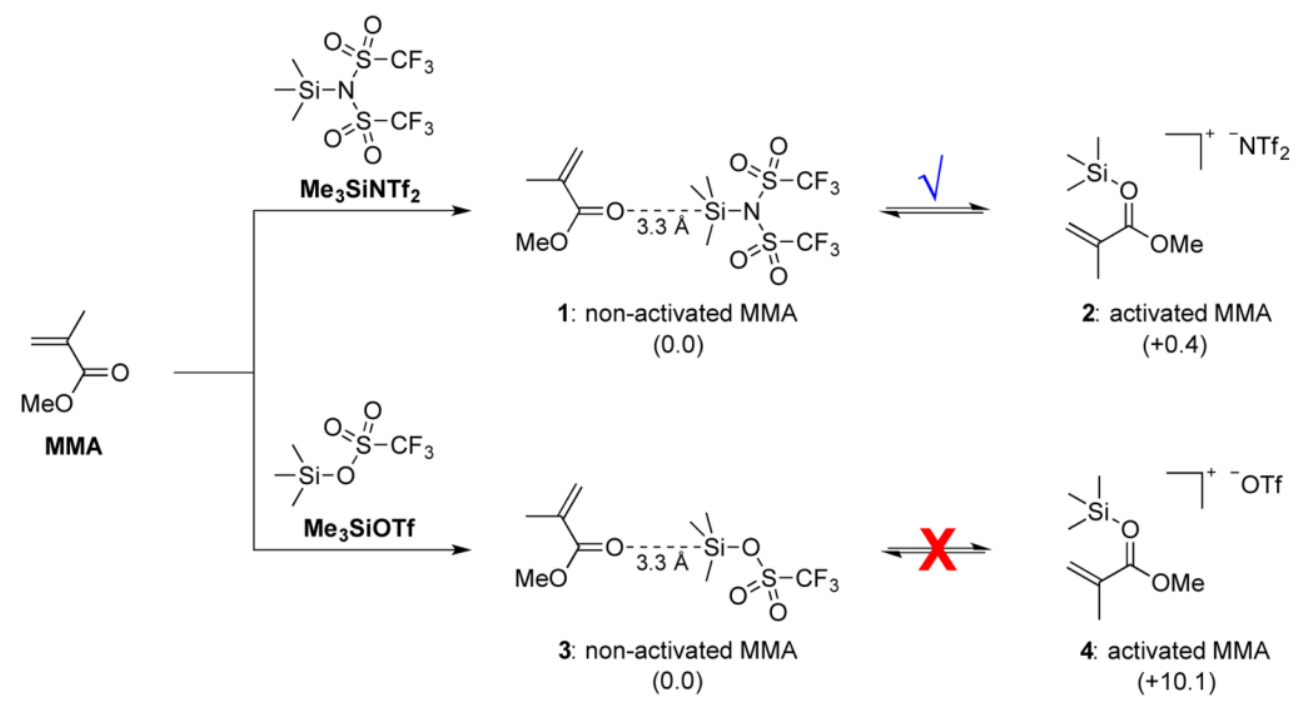

Scheme 3. Relative energies ( $\Delta E$ in $\mathrm{kcal} / \mathrm{mol}$ ) of compounds formed between MMA and $\mathrm{Me}_{3} \mathrm{SiX}\left(\mathrm{X}=\mathrm{NTf}_{2}\right.$ or OTf) calculated at the M06-2X(SMD-toluene)/6-311++G**//M06-2X/6-31G** level of theory.

Thus, only $\mathrm{Me}_{3} \mathrm{SiNTf}_{2}$ was considered for the rest of the study because of its unique ability to mediate activation, and further polymerization of MMA, when associated with TTMPP-. The association between this silane LA and TTMPP was then theoretically investigated (Figure 9). Two minima, corresponding to a FLPlike structure (5), on one hand, and to a P-silyl phosphonium (6), on the other hand, could be identified on the PES, 5 lying $10 \mathrm{kcal} / \mathrm{mol}$ above $\mathbf{6}$ (Figure S11 in ESI for details). Compound $\mathbf{6}$ was characterized by a P-Si bond distance of $2.393 \AA$ and a long Si...N distance of $3.047 \AA$, indicative of a very weak interaction of the $\mathrm{NTf}_{2}$ anion with the silicon centre $(\mathrm{N} . . \mathrm{P} \sim 5.5 \AA)$. Interestingly, the theoretical ${ }^{31} \mathrm{P}$ NMR chemical shift calculated for 6 ( $\delta^{31} \mathrm{P}^{\text {theo: }}$ - $\left.-36.4 \mathrm{ppm}\right)$ correlated well with experimental data $\left(\delta^{31} \mathrm{P}^{\exp }:-34.2 \mathrm{ppm}\right)$, supporting its formation in solution. As expected for the FLP structure 5, a rather long P...Si distance was calculated (3.778 $\AA$ ), while the Si-N bond distance was short $(1.921 \AA$ ). NBO and QTAIM analyses suggested that this FLP structure was stabilized thanks to weak donor $\rightarrow$ acceptor interaction $\left[\mathrm{LP}(\mathrm{P}) \rightarrow \mathrm{LP}(\mathrm{Si})^{*}: 6.5 \mathrm{kcal} / \mathrm{mol}\right]$ and multiple hydrogen bonds, with an average value of the electron density $\rho(r)$ around 0.01 e.bohr ${ }^{-3}$ (Table S1 in ESI for details). A transition state (TS) connecting 5 and $\mathbf{6}$ could be located on the PES (Figure S11 in ESI for details) and a low activation barrier $(1.8 \mathrm{kcal} / \mathrm{mol})$ was computed for the formation of $\mathbf{5}$ from $\mathbf{6}$. Overall, these DFT calculations evidenced that FLP 5 was certainly the form activating MMA in solution. 


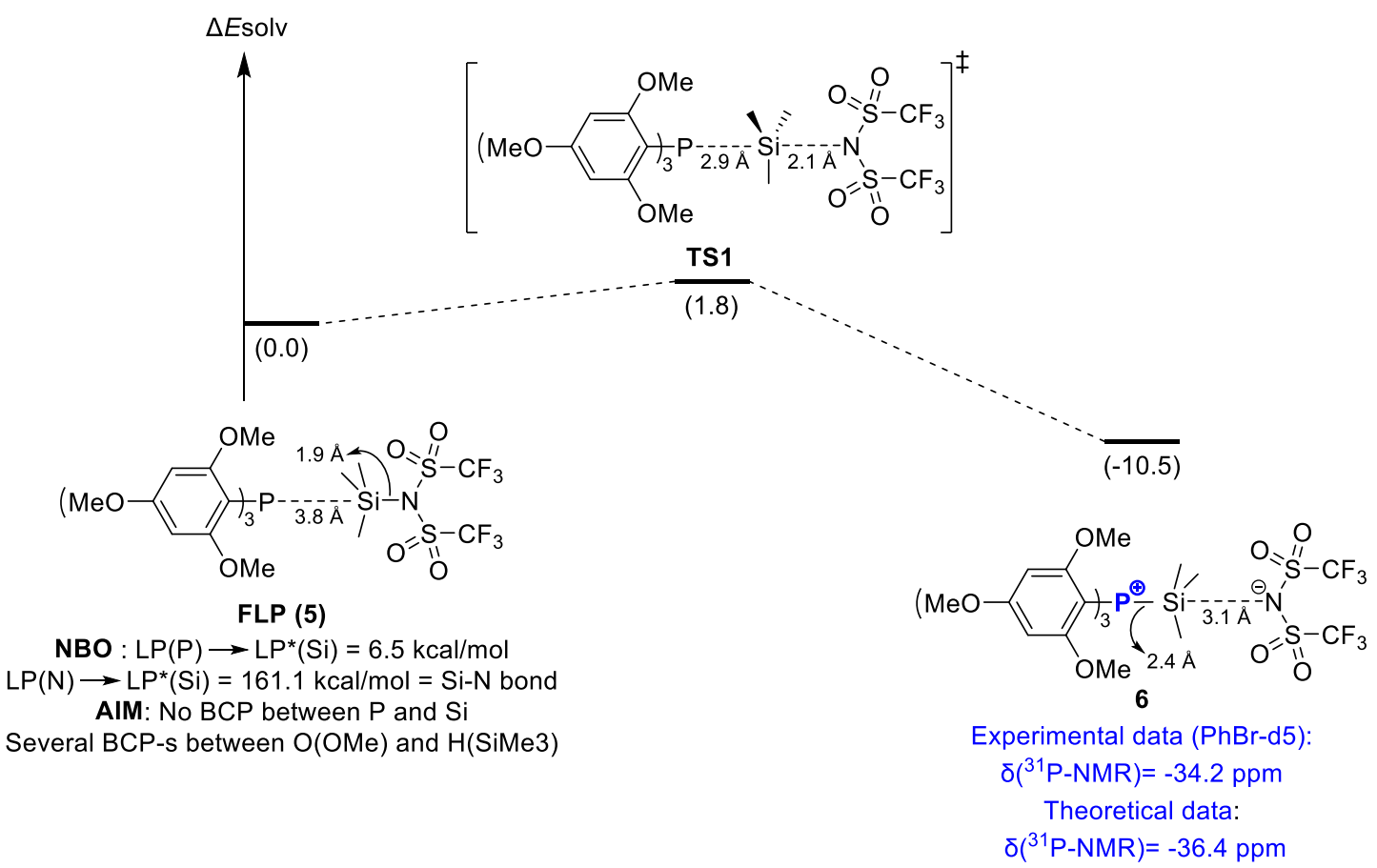

Figure 9. Association between $\mathrm{Me}_{3} \mathrm{SiNTf}_{2}$ and TTMPP at the M06-2X(SMD-toluene)/6-311++G**//M06-2X/6-31G** level of theory. Inter-conversion process between FLP 5 and adduct 6. Relative energies, $\Delta E$, in $\mathrm{kcal} / \mathrm{mol}$ and ${ }^{31} \mathrm{P}-\mathrm{NMR}$ chemical shifts (experimental and theoretical) in ppm.

To further elucidate the role of this phosphine/silane in the LPP process, the initiation step, that is the reaction of 5 with one equivalent of MMA, was first computed, as well as the phospha-Michael addition of TTMPP to MMA, in absence of $\mathrm{Me}_{3} \mathrm{SiNTf}_{2}$ (Figure S12 in ESI for details). For the latter conjugate addition, the activation barrier was predicted relatively low $(11.2 \mathrm{kcal} / \mathrm{mol})$ but the formation of the corresponding zwitterionic phosphonium enolate (zwitterion 1, Figure S12) was found to be thermodynamically unfavorable, both the final product and the corresponding TS being quasi isoenergetic. In contrast, the FLP 5-mediated conjugate addition was predicted to occur through a pre-organized complex (Figure 10; see also Figure S13 for geometrical features and Table S2 for AIM analysis), where the phosphine interacted with the activated MMA through multiple H-bonds. In contrast to the $\mathrm{Me}_{3} \mathrm{SiNTf}_{2}$-free reaction, the conjugate addition of the phosphine was found to be strongly exothermic $\left(\Delta E_{\mathrm{rxn}}:-24.8 \mathrm{kcal} / \mathrm{mol}\right)$ with an activation barrier of only $5.2 \mathrm{kcal} / \mathrm{mol}$, that is $6 \mathrm{kcal} / \mathrm{mol}$ lower than that calculated for the reaction in absence of $\mathrm{Me}_{3} \mathrm{SiNTf}_{2}$. This result again highlighted the key role of the dual nucleophilic/electrophilic activation on both the kinetic and the thermodynamic of the first addition of MMA. ${ }^{78}$

It is noteworthy in this mechanism that although the pre-organized complex could be in equilibrium with the P-Silyl phosphonium 6 via the FLP 5, the low activation barrier of the conjugate addition of the $1^{\text {st }}$ molecule of activated MMA (around $5.2 \mathrm{kcal} / \mathrm{mol}$ ) and the strong stabilization of the ensuing phosphonium silyl ketene acetal (PSKA-1, Figure 10 and Figure S13) made this initiation step much favored than the formation of 6, in presence of MMA.

Addition of (PSKA-1) to a second activated-MMA molecule was then investigated as a model of the propagation step of the LPP. This step was computed to occur with a low activation barrier $\left(\Delta E^{\#}: 6.7 \mathrm{kcal} / \mathrm{mol}\right)$, similar to that determined for the initiation step. This reaction also proved thermodynamically favored (PSKA2, $\Delta E:-9.5 \mathrm{kcal} / \mathrm{mol}$ ), but to a smaller extent compared to the first step. ${ }^{79}$ 


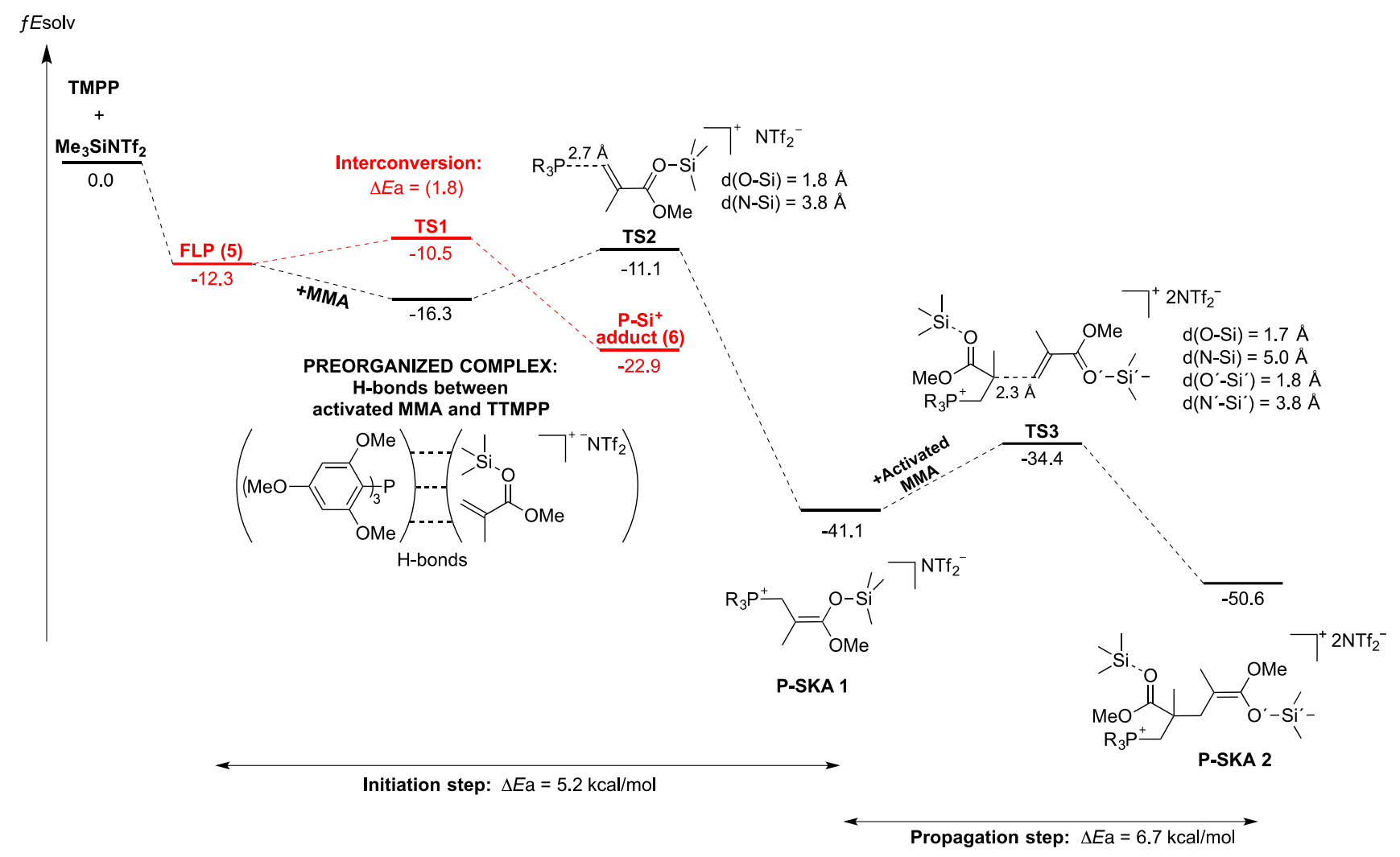

Figure 10. Energy profile ( $\Delta E$ in $\mathrm{kcal} / \mathrm{mol}$ ) computed at the M06-2X(SMD-toluene)/6-311++G**//M06-2X/6$31 \mathrm{G}^{* *}$ level. Initiation and propagation steps of $\mathrm{Me}_{3} \mathrm{SiNTf}_{2} / \mathrm{TTMPP}$ catalyzed polymerization of MMA and plausible inter-conversion between the pre-organized complex and FLP 5.

\section{CONCLUSION}

The Lewis pair-mediated polymerization (LPP) of MMA can be directly initiated at room temperature in toluene using different commercial phosphines $\left(\mathrm{P}^{t} \mathrm{Bu}_{3}, \mathrm{P}^{n} \mathrm{Bu}_{3}\right.$ or TTMPP) in conjunction with a simple silane, namely and specifically, $\mathrm{Me}_{3} \mathrm{SiNTf}_{2}$, rather than $\mathrm{Me}_{3} \mathrm{SiOTf}$, as demonstrated by a joint experimental-theoretical approach. When probing the LP combining TTMPP and $\mathrm{Me}_{3} \mathrm{SiNTf}_{2}$ in more details, the interaction between the phosphorus and the silicon centers appears to be weak, so that the resulting P-silyl phosphonium adduct may be in equilibrium with the corresponding FLP. In other words, the P-silylphosphonium behaves as a masked FLP in solution. As a matter of fact, this FLP represents the active form for the activation of MMA, and for the initiation step of the polymerization as well. The ensuing phosphonium silyl ketene acetal then propagates the polymerization via a dual/cooperative mechanism, by successive 1,4-conjugate additions onto the monomer activated by the Lewis acid. DFT calculations have highlighted the dual nucleophilic / electrophilic activation on both the kinetic and thermodynamic of the first addition of MMA. Thus, two equivalents of $\mathrm{Me}_{3} \mathrm{SiNTf}_{2}$ are required, in agreement with experimental and theoretical studies. The combination of TTMPP with $\mathrm{Me}_{3} \mathrm{SiNTf}_{2}$ affords an unprecedented fully organic LP/FLP that allows achieving well-defined PMMA's under mild conditions, i.e. in toluene at $25{ }^{\circ} \mathrm{C}$, with molecular weights increasing linearly with the initial $[\mathrm{MMA}]_{0} /[\mathrm{TTMPP}]_{0}$ ratio. These results also extend the scope of LPP, by introducing metal-free LP/FLP incorporating a weak Lewis acid and a simple phosphine, which combines relatively high activity and good chemoselectivity. Future work will focus on phosphine/silane-mediated LPP of different monomers, as well as on the investigation of novel LP's/FLP's for polymer synthesis. 


\section{REFERENCES}

1. Allen, A. E.; MacMillan, D. W. C., Synergistic Catalysis: A Powerful Synthetic Strategy for New Reaction Development. Chem. Sci. 2012, 3, 633.

2. Raup, D. E. A.; Cardinal-David, B.; Holte, D.; Scheidt, K. A., Cooperative Catalysis by Carbenes and Lewis Acids in a Highly Stereoselective Route to $\gamma$-Lactams. Nat. Chem. 2010, 2, 766.

3. Grossmann, A.; Enders, D., N-Heterocyclic Carbene Catalyzed Domino Reactions. Angew. Chem. Int. Ed. 2012, 51, 314-325.

4. Cohen, D. T.; Scheidt, K. A., Cooperative Lewis Acid/N-heterocyclic Carbene Catalysis. Chem. Sci. 2012, 3, (1), 53-57.

5. Du, Z.; Shao, Z., Combining Transition Metal Catalysis and Organocatalysis - An Update. Chem. Soc. Rev. 2013, 42, (3), 1337-1378.

6. Park, Y. J.; Park, J.-W.; Jun, C.-H., Metal-Organic Cooperative Catalysis in C-H and C-C Bond Activation and its Concurrent Recovery. Acc. Chem. Res. 2008, 41, (2), 222-234.

7. Shao, Z.; Zhang, H., Combining Transition Metal Catalysis and Organocatalysis: A Broad New Concept for Catalysis. Chem. Soc. Rev. 2009, 38, (9), 2745-2755.

8. Piedra-Arroni, E.; Amgoune, A.; Bourissou, D., Dual Catalysis: New Approaches for the Polymerization of Lactones and Polar Olefins. Dalton Trans. 2013, 42, (25), 9024-9029.

9. $\quad$ Kiesewetter, M. K.; Shin, E. J.; Hedrick, J. L.; Waymouth, R. M., Organocatalysis: Opportunities and Challenges for Polymer Synthesis. Macromolecules 2010, 43, (5), 2093-2107.

10. Ottou, W. N.; Sardon, H.; Mecerreyes, D.; Vignolle, J.; Taton, D., Update and Challenges in Organo-Mediated Polymerization Reactions. Prog. Polym. Sci. 2016, 56, 64-115.

11. Zhang, Y.; Miyake, G. M.; John, M. G.; Falivene, L.; Caporaso, L.; Cavallo, L.; Chen, E. Y. X., Lewis Pair Polymerization by Classical And Frustrated Lewis Pairs: Acid, Base and Monomer Scope and Polymerization Mechanism. Dalton Trans. 2012, 41, (30), 9119-9134.

12. Degee, P.; Dubois, P.; Jerome, R., Bulk Polymerization of Lactides Initiated by Aluminium Isopropoxide. 2. Beneficial Effect of Lewis Bases and Transfer Agents. Macromol. Chem. Phys. 1997, 198, (6), 1973-1984.

13. Degee, P.; Dubois, P.; Jerome, R.; Jacobsen, S.; Fritz, H. G., New Catalysis for Fast Bulk Ring-Opening Polymerization of Lactide Monomers. Macromol. Symp. 1999, 144, 289-302.

14. Patel, D.; Liddle, S. T.; Mungur, S. A.; Rodden, M.; Blake, A. J.; Arnold, P. L., Bifunctional Yttrium(III) and Titanium(IV) NHC Catalysts for Lactide Polymerization. Chem. Commun. 2006, 1124-1126.

15. Arnold, P. L.; Casely, I. J.; Turner, Z. R.; Bellabarba, R.; Tooze, R. B., Magnesium and Zinc Complexes of Functionalised, Saturated N-heterocyclic Carbene Ligands: Carbene Lability and Functionalisation, and Lactide Polymerisation Catalysis. Dalton Trans. 2009, 7236-7247.

16. Pietrangelo, A.; Hillmyer, M. A.; Tolman, W. B., Stereoselective and Controlled Polymerization of D,L-Lactide Using Indium(III) Trichloride. Chem. Commun. 2009, 2736-2737.

17. Pietrangelo, A.; Knight, S. C.; Gupta, A. K.; Yao, L. J.; Hillmyer, M. A.; Tolman, W. B., Mechanistic Study of the Stereoselective Polymerization of D,L-Lactide using Indium(III) Halides. J. Am. Chem. Soc. 2010, $132,11649-11657$.

18. Piedra-Arroni, E.; Brignou, P.; Amgoune, A.; Guillaume, S. M.; Carpentier, J. F.; Bourissou, D., A Dual Organic/Organometallic Approach for Catalytic Ring-Opening Polymerization. Chem. Commun. 2011, 47, (35), 98289830 .

19. Brignou, P.; Guillaume, S. M.; Roisnel, T.; Bourissou, D.; Carpentier, J.-F., Discrete Cationic Zinc and Magnesium Complexes for Dual Organic/Organometallic-Catalyzed Ring-Opening Polymerization of Trimethylene Carbonate. Chem. Eur. J. 2012, 18, 9360-9370.

20. Naumann, S.; Scholten, P. B. V.; Wilson, J. A.; Dove, A. P., Dual Catalysis for Selective Ring-Opening Polymerization of Lactones: Evolution toward Simplicity. J. Am. Chem. Soc 2015, 137, (45), 14439-14445.

21. Koeller, S.; Kadota, J.; Peruch, F.; Deffieux, A.; Pinaud, N.; Pianet, I.; Massip, S.; Leger, J.-M.; Desvergne, J.-P.; Bibal, B., (Thio)Amidoindoles and (Thio)Amidobenzimidazoles: An Investigation of their Hydrogen-Bonding and Organocatalytic Properties in the Ring-Opening Polymerization of Lactide. Chem. Eur. J. 2010, 16, 4196-4205.

22. Kadota, J.; Pavlovic, D.; Desvergne, J. P.; Bibal, B.; Peruch, F.; Deffieux, A., Ring-Opening Polymerization of LLactide Catalyzed by an Organocatalytic System Combining Acidic and Basic Sites. Macromolecules 2010, 43, (21), 8874-8879.

23. Coady, D. J.; Engler, A. C.; Horn, H. W.; Bajjuri, K. M.; Fukushima, K.; Jones, G. O.; Nelson, A.; Rice, J. E.; Hedrick, J. L., Catalyst Chelation Effects in Organocatalyzed Ring-Opening Polymerization of Lactide. ACS Macro Lett. 2012, 1, (1), 19-22.

24. Kazakov, O. I.; Datta, P. P.; Isajani, M.; Kiesewetter, E. T.; Kiesewetter, M. K., Cooperative Hydrogen-Bond Pairing in Organocatalytic Ring-Opening Polymerization. Macromolecules 2014, 47, (21), 7463-7468.

25. Kazakov, O. I.; Kiesewetter, M. K., Cocatalyst Binding Effects in Organocatalytic Ring-Opening Polymerization of L-Lactide. Macromolecules 2015, 48, (17), 6121-6126.

26. Welch, G. C.; San Juan, R. R.; Masuda, J. D.; Stephan, D. W., Reversible, Metal-free Hydrogen Activation. Science 2006, 314, (5802), 1124-1126.

27. Morton, J. G. M.; Dureen, M. A.; Stephan, D. W., Ring-Opening of Cyclopropanes by "Frustrated Lewis Pairs". Chem. Commun. 2010, 46, (47), 8947-8949. 
28. Peuser, I.; Neu, R. C.; Zhao, X.; Ulrich, M.; Schirmer, B.; Tannert, J. A.; Kehr, G.; Fröhlich, R.; Grimme, S.; Erker, G.; Stephan, D. W., CO2 and Formate Complexes of Phosphine/Borane Frustrated Lewis Pairs. Chem. Eur. J. 2011, $17,(35), 9640-9650$.

29. Neu, R. C.; Otten, E.; Lough, A.; Stephan, D. W., The Synthesis and Exchange Chemistry of Frustrated Lewis Pair-Nitrous Oxide Complexes. Chem. Sci. 2011, 2, (1), 170-176.

30. Neu, R. C.; Menard, G.; Stephan, D. W., Exchange Chemistry of tBu3P(CO2)B(C6F5)2Cl. Dalton Trans. 2012, 41, (30), 9016-9018.

31. Stephan, D. W.; Erker, G., Frustrated Lewis Pair Chemistry: Development and Perspectives. Angew. Chem. Int. Ed. 2015, 54, (22), 6400-6441.

32. Zhang, Y.; Miyake, G. M.; Chen, E. Y. X., Alane-Based Classical and Frustrated Lewis Pairs in Polymer Synthesis: Rapid Polymerization of MMA and Naturally Renewable Methylene Butyrolactones into High-MolecularWeight Polymers. Angew. Chem. Int. Ed. 2010, 49, (52), 10158-10162.

33. Chen, E. X., Polymerization by Classical and Frustrated Lewis Pairs. In Frustrated Lewis Pairs II, Erker, G.; Stephan, D. W., Eds. Springer Berlin Heidelberg: 2013; Vol. 334, pp 239-260.

34. He, J.; Zhang, Y.; Falivene, L.; Caporaso, L.; Cavallo, L.; Chen, E. Y. X., Chain Propagation and Termination Mechanisms for Polymerization of Conjugated Polar Alkenes by [Al]-Based Frustrated Lewis Pairs. Macromolecules 2014, 47, (22), 7765-7774.

35. Piedra-Arroni, E.; Ladavière, C.; Amgoune, A.; Bourissou, D., Ring-Opening Polymerization with Zn(C6F5)2Based Lewis Pairs: Original and Efficient Approach to Cyclic Polyesters. J. Am. Chem. Soc. 2013, 135, (36), 1330613309.

36. Chen, J.; Chen, E. Y. X., Lewis Pair Polymerization of Acrylic Monomers by N-Heterocyclic Carbenes and $\mathrm{B}(\mathrm{C6F5}) 3$. Isr. J. Chem. 2015, 55, (2), 216-225.

37. Jia, Y.-B.; Ren, W.-M.; Liu, S.-J.; Xu, T.; Wang, Y.-B.; Lu, X.-B., Controlled Divinyl Monomer Polymerization Mediated by Lewis Pairs: A Powerful Synthetic Strategy for Functional Polymers. ACS Macro Lett. 2014, 3, (9), 896-899.

38. Fèvre, M.; Vignolle, J.; Heroguez, V.; Taton, D., Tris(2,4,6-trimethoxyphenyl)phosphine (TTMPP) as Potent Organocatalyst for Group Transfer Polymerization of Alkyl (Meth)Acrylates. Macromolecules 2012, 45, (19), $7711-7718$.

39. Ottou, W. N.; Bourichon, D.; Vignolle, J.; Wirotius, A.-L.; Robert, F.; Landais, Y.; Sotiropoulos, J.-M.; Miqueu, K.; Taton, D., Cyclodimerization versus polymerization of Methyl Methacrylate Induced by N-heterocyclic Carbenes: A Combined Experimental and Theoretical Study. Chem. Eur. J. 2014, 20, (14), 3989-3997.

40. Ottou, W. N.; Bourichon, D.; Vignolle, J.; Wirotius, A.-L.; Robert, F.; Landais, Y.; Sotiropoulos, J.-M.; Miqueu, K.; Taton, D., From the N-Heterocyclic Carbene-Catalyzed Conjugate Addition of Alcohols to the Controlled Polymerization of (Meth)Acrylates. Chem. Eur. J. 2015, 21, (26), 9447-9453.

41. Raynaud, J.; Ciolino, A.; Baceiredo, A.; Destarac, M.; Bonnette, F.; Kato, T.; Gnanou, Y.; Taton, D., Harnessing The Potential of N-heterocyclic Carbenes for the Rejuvenation of Group-Transfer Polymerization of (Meth)Acrylics. Angew. Chem., Int. Ed. 2008, 47, 5390-5393.

42. Raynaud, J.; Gnanou, Y.; Taton, D., Group Transfer Polymerization of (Meth)acrylic Monomers Catalyzed by NHeterocyclic Carbenes and Synthesis of all Acrylic Block Copolymers: Evidence for an Associative Mechanism. Macromolecules 2009, 42, (16), 5996-6005.

43. Raynaud, J.; Liu, N.; Gnanou, Y.; Taton, D., Expanding the Scope of Group Transfer Polymerization using NHeterocyclic Carbenes as Catalysts: Application to Miscellaneous (Meth)Acrylic Monomers and Kinetic Investigations. Macromolecules 2010, 43, (21), 8853-8861.

44. Raynaud, J.; Liu, N.; Fevre, M.; Gnanou, Y.; Taton, D., No Matter the Order of Monomer Addition for the Synthesis of Well-Defined Block Copolymers by Sequential Group Transfer Polymerization using N-heterocyclic Carbenes as Catalysts. Polym. Chem. 2011, 2, (8), 1706-1712.

45. Dilman, A. D.; Ioffe, S. L., Carbon-Carbon Bond Forming Reactions Mediated by Silicon Lewis Acids. Chem. Rev. 2003, 103, (3), 733-772.

46. Mathieu, B.; Ghosez, L., N-Trimethylsilyl-bis(trifluoromethanesulfonyl)imide: A better Carbonyl Activator than Trimethylsilyl triflate. Tetrahedron Lett. 1997, 38, (31), 5497-5500.

47. Mathieu, B.; Ghosez, L., Trimethylsilyl bis(trifluoromethanesulfonyl)imide as a Tolerant and Environmentally Benign Lewis Acid Catalyst of the Diels-Alder Reaction. Tetrahedron 2002, 58, (41), 8219-8226.

48. Ishihara, K.; Hiraiwa, Y.; Yamamoto, H., Crucial Role of the Ligand of Silyl Lewis Acid in The Mukaiyama Aldol Reaction. Chem. Commun. 2002, (15), 1564-1565.

49. von Wolff, N.; Lefèvre, G.; Berthet, J. C.; Thuéry, P.; Cantat, T., Implications of CO2 Activation by Frustrated Lewis Pairs in the Catalytic Hydroboration of CO2: A View using N/Si+ Frustrated Lewis Pairs. ACS Catalysis 2016, 6, (7), 4526-4535.

50. Waerder, B.; Pieper, M.; Körte, L. A.; Kinder, T. A.; Mix, A.; Neumann, B.; Stammler, H.-G.; Mitzel, N. W., A Neutral Silicon/Phosphorus Frustrated Lewis Pair. Angew. Chem., Int. Ed. 2015, 54, (45), 13416-13419.

51. Weicker, S. A.; Stephan, D. W., Activation of Carbon Dioxide by Silyl Triflate-Based Frustrated Lewis Pairs. Chem. Eur. J. 2015, 21, (37), 13027-13034.

52. $\quad$ Kakuchi, R.; Chiba, K.; Fuchise, K.; Sakai, R.; Satoh, T.; Kakuchi, T. Strong Brønsted Acid as a Highly Efficient Promoter for Group Transfer Polymerization of Methyl Methacrylate. Macromolecules 2009, 42 (22), 8747-8750.

53. Chen, Y.; Takada, K.; Fuchise, K.; Satoh, T.; Kakuchi, T. Synthesis of Syndiotactic-rich Star-shaped Poly(methyl methacrylate) by Core-first Group Transfer Polymerization Using N- (Trimethylsilyl)bis(trifluoromethanesulfonyl)imide. J. Polym. Sci., Part A: Polym. Chem. 2012, 50 (16), 3277-3285. 
54. Takada, K.; Ito, T.; Kitano, K.; Tsuchida, S.; Takagi, Y.; Chen, Y.; Satoh, T.; Kakuchi, T. Synthesis of Homopolymers, Diblock Copolymers, and Multiblock Polymers by Organocatalyzed Group Transfer Polymerization of Various Acrylate Monomers. Macromolecules 2015, 48 (3), 511-519.

55. Gaussian 09, Revision D.01, Frisch, M. J.; Trucks, G. W.; Schlegel, H. B.; Scuseria, G. E.; Robb, M. A.; Cheeseman, J. R.; Scalmani, G.; Barone, V.; Mennucci, B.; Petersson, G. A.; Nakatsuji, H.; Caricato, M.; Li, X.; Hratchian, H. P.; Izmaylov, A. F.; Bloino, J.; Zheng, G.; Sonnenberg, J. L.; Hada, M.; Ehara, M.; Toyota, K.; Fukuda, R.; Hasegawa, J.; Ishida, M.; Nakajima, T.; Honda, Y.; Kitao, O.; Nakai, H.; Vreven, T.; Montgomery, J. A., Jr.; Peralta, J. E.; Ogliaro, F.; Bearpark, M.; Heyd, J. J.; Brothers, E.; Kudin, K. N.; Staroverov, V. N.; Kobayashi, R.; Normand, J.; Raghavachari, K.; Rendell, A.; Burant, J. C.; Iyengar, S. S.; Tomasi, J.; Cossi, M.; Rega, N.; Millam, J. M.; Klene, M.; Knox, J. E.; Cross, J. B.; Bakken, V.; Adamo, C.; Jaramillo, J.; Gomperts, R.; Stratmann, R. E.; Yazyev, O.; Austin, A. J.; Cammi, R.; Pomelli, C.; Ochterski, J. W.; Martin, R. L.; Morokuma, K.; Zakrzewski, V. G.; Voth, G. A.; Salvador, P.; Dannenberg, J. J.; Dapprich, S.; Daniels, A. D.; Farkas, Ö.; Foresman, J. B.; Ortiz, J. V.; Cioslowski, J.; Fox, D. J. Gaussian, Inc., Wallingford CT, 2009.

56. Zhao, Y.; Truhlar, D. G., The M06 Suite of Density Functionals for Main Group Thermochemistry, Thermochemical Kinetics, Noncovalent Interactions, Excited States, and Transition Elements: Two New Functionals and Systematic Testing of Four M06-class Functionals and 12 other Functionals. Theor. Chem. Acc. 2008, 120, (1), $215-241$.

57. Hariharan, P. C.; Pople, J. A., The Influence Of Polarization Functions on Molecular Orbital Hydrogenation Energies. Theor.Chim. Acta 1973, 28, (3), 213-222.

58. Gonzalez, C.; Schlegel, H. B., An Improved Algorithm for Reaction Path Following. J. Chem. Phys. 1989, 90, (4), 2154-2161.

59. Gonzalez, C.; Schlegel, H. B., Reaction Path Following in Mass-weighted Internal Coordinates. J. Phys. Chem. 1990, 94, (14), 5523-5527.

60. Marenich, A. V.; Cramer, C. J.; Truhlar, D. G., Universal Solvation Model Based on Solute Electron Density and on a Continuum Model of the Solvent Defined by the Bulk Dielectric Constant and Atomic Surface Tensions. J. Phys. Chem. B 2009, 113, (18), 6378-6396.

61. Bader, R. F. W., Atoms in Molecules: A Quantum Theory. Oxford University Press: New-York Ed: 1990.

62. Bader, R. F. W., A Quantum Theory of Molecular Structure and its Applications. Chem. Rev. 1991, 91, (5), 893-

928.

63. AIMAll (Version 10.10.11), Todd A. Keith, 2010 (aim.tkgristmill.com).

64. Reed, A. E.; Curtiss, L. A.; Weinhold, F., Intermolecular Interactions from a Natural Bond Orbital, DonorAcceptor Viewpoint. Chem. Rev. 1988, 88, (6), 899-926.

65. Foster, J. P.; Weinhold, F., Natural Hybrid Orbitals. J. Am. Chem. Soc. 1980, 102, (24), 7211-7218.

66. Reed, A. E.; Weinhold, F., Natural Localized Molecular Orbitals. J. Chem. Phys. 1985, 83, (4), $1736-1740$.

67. Ditchfield, R., Self-consistent Perturbation Theory of Diamagnetism. Mol. Phys. 1974, 27, (4), $789-807$.

68. Wolinski, K.; Hinton, J. F.; Pulay, P., Efficient Implementation of the Gauge-Independent Atomic Orbital Method for NMR Chemical Shift Calculations. J. Am. Chem. Soc. 1990, 112, (23), 8251-8260.

69. Kutzelnigg, W.; Fleischer, U.; Schindler, M., NMR Basic Principles and progress. Springer-Verlag: Heidelberg, 1990; Vol. 23.

70. Mendoza-Espinosa, D.; Donnadieu, B.; Bertrand, G., Synthesis of 4- and 4,5-Functionalized Imidazol-2-ylidenes from A Single 4,5-Unsubstituted Imidazol-2-ylidene. J. Am. Chem. Soc. 2010, 132, (21), 7264-7265.

71. Whittell, G. R.; Balmond, E. I.; Robertson, A. P. M.; Patra, S. K.; Haddow, M. F.; Manners, I., Reactions of Amine- and Phosphane-Borane Adducts with Frustrated Lewis Pair Combinations of Group 14 Triflates and Sterically Hindered Nitrogen Bases. Eur. J. Inorg. Chem. 2010, (25), 3967-3975.

72. Wada, M.; Higashizaki, S., A Highly Basic triphenylphosphine, [2,4,6-(MeO)3C6H2]3P. J. Chem. Soc., Chem. Commun. 1984, (7), 482-483.

73. Scholten, M. D.; Hedrick, J. L.; Waymouth, R. M., Group Transfer Polymerization of Acrylates Catalyzed by NHeterocyclic Carbenes. Macromolecules 2008, 41, (20), 7399-7404.

74. Fuchise, K.; Chen, Y.; Satoh, T.; Kakuchi, T., Recent Progress in Organocatalytic Group Transfer Polymerization. Polym. Chem. 2013, 4 (16), 4278-4291.

75. Takada, K.; Fuchise, K.; Kubota, N.; Ito, T.; Chen, Y.; Satoh, T.; Kakuchi, T., Synthesis of $\alpha-, \omega-$, and $\alpha, \omega$-EndFunctionalized Poly(n-butyl acrylate)s by Organocatalytic Group Transfer Polymerization Using Functional Initiator and Terminator. Macromolecules 2014, 47 (16), 5514-5525.

76. Chen, Y.; Takada, K.; Kubota, N.; Eric, O.-T.; Ito, T.; Isono, T.; Satoh, T.; Kakuchi, T., Synthesis of EndFunctionalized Poly(methyl methacrylate) by Organocatalyzed Group Transfer Polymerization Using Functional Silyl Ketene Acetals and $\alpha$-phenylacrylates. Polym. Chem. 2015, 6 (10), 1830-1837.

77. Hatada, K.; Kitayama, T., Stereochemistry of Polymers. In NMR Spectroscopy of Polymers, Springer Berlin Heidelberg: 2004; pp 73-93.

78. See ESI. The geometrical features of the TS (TS2) revealed that it is an early TS (P...C: $2.702 \AA$; O-Si: $1.758 \AA$; N...Si: $3.796 \AA$ ), with P...C distance longer than in the non-assisted phospha-Michael addition $(2.702$ versus $2.023 \AA)$. In addition, NBO analysis of TS2 shows a stabilizing interaction between the lone pair of the $\mathrm{P}$ atom of the phosphine and the $\Pi^{*} \mathrm{C}=\mathrm{C}$ of the activated MMA of $24.4 \mathrm{kcal} / \mathrm{mol}$.

79. See ESI Figure S14. It is notable that in this transition state (TS3) the C...C distance is around $2.3 \AA$ and the silicon atom is connected to the oxygen $(1.7 \AA)$ like in TS2. 